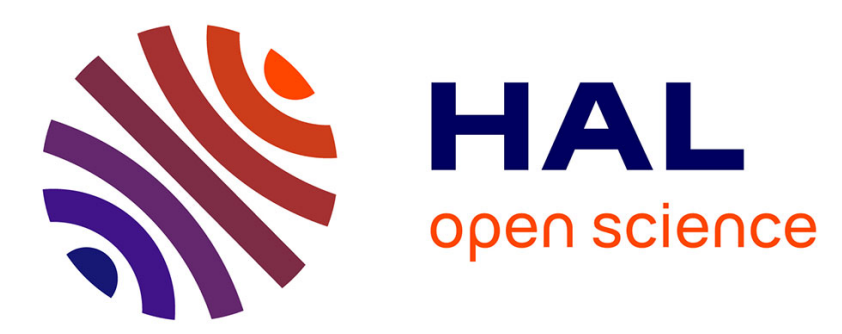

\title{
Mechanical insights into the development of fracture corridors in layered rocks
}

\author{
Ghislain de Joussineau, Jean-Pierre Petit
}

\section{To cite this version:}

Ghislain de Joussineau, Jean-Pierre Petit. Mechanical insights into the development of fracture corridors in layered rocks. Journal of Structural Geology, 2021, 144, pp.104278. 10.1016/j.jsg.2021.104278 . hal-03393738

\section{HAL Id: hal-03393738 \\ https://hal.science/hal-03393738}

Submitted on 27 Oct 2021

HAL is a multi-disciplinary open access archive for the deposit and dissemination of scientific research documents, whether they are published or not. The documents may come from teaching and research institutions in France or abroad, or from public or private research centers.
L'archive ouverte pluridisciplinaire HAL, est destinée au dépôt et à la diffusion de documents scientifiques de niveau recherche, publiés ou non, émanant des établissements d'enseignement et de recherche français ou étrangers, des laboratoires publics ou privés. 


\title{
Mechanical insights into the development of fracture corridors in layered rocks
}

\author{
Ghislain de Joussineau ${ }^{\mathrm{a}, \mathrm{b}, *}$, Jean-Pierre Petit ${ }^{\mathrm{c}}$ \\ ${ }^{a}$ Beicip-Franlab, 232 Avenue Napoléon Bonaparte, 92502 Rueil-Malmaison Cedex, France \\ ${ }^{\mathrm{b}}$ Formerly Géosciences Montpellier, France \\ ${ }^{\mathrm{c}}$ Géosciences Montpellier (UMR 5243), Université de Montpellier, Campus Triolet, Case Courrier 060, Place Eugène Bataillon, 34095 Montpellier Cedex 5, France
}

\section{A R T I C L E I N F O}

\section{Keywords:}

Fracture corridors

Layered rocks

Fracture clustering mechanisms

Elastic models

\begin{abstract}
A B S T R A C T
Fracture corridors are ubiquitous features formed by closely-spaced sub-parallel fractures, typically occurring in brittle mechanical units. They are important because they can form drains for fluids in hydrocarbon reservoirs and aquifers. Their development is sometimes associated with local structural or sedimentary heterogeneities but other situations exist where their mechanical origin remains obscure. In this paper, we investigate the combined role of contrasts in mechanical properties of consecutive layers and pre-existing fracturing in the formation of fracture corridors in sedimentary rocks, using 2D elastic finite element models.

Our models contain five bonded layers with contrasted elastic properties and two pre-existing open fractures in the central layer. Firstly, we compute stress fields in the models submitted to biaxial compression and compression-extension plane strain loading. We identify favorable stress conditions supporting further fracturing in both situations. Secondly, we investigate fracture clustering mechanisms by means of quasi-static fracture propagations in identified areas of tensile stress. We characterize three situations leading to the development of incipient fracture corridors and discuss their geological implications. Finally, we propose a new conceptual model for the formation of these features in the subsurface, with important consequences for the characterization and modeling of fractured reservoirs.
\end{abstract}

\section{Introduction}

Fracture corridors, which can simply be defined as arrays of closely spaced fractures (mostly joints, and sheared joints or veins) or tabular zones of significantly increased fracture intensity (Peacock et al., 2016), are quite common structural objects. They could be compared to fracture clusters or fracture swarms (Angelier et al., 1997; Bevan and Hancock, 1986; Laubach, 1991; Laubach et al., 1995; Gillespie et al., 2001; Belayneh et al., 2007), however with a distinction. The latter terms convey the same characteristic idea of directionality or narrowness than corridors, but not necessarily that they can be a concentration of sub-parallel fractures, denser (more closely spaced) than those of the surrounding rocks (background fractures) (Fig. 1a-d).

The fracture corridors considered in this paper are formed by joints (as defined in Pollard and Aydin, 1988, and Schultz and Fossen, 2008). In sedimentary rocks, they are generally confined to the thickness of a brittle mechanical unit (Fig. 1a and e). Their individual constitutive fractures usually do not crosscut the entire thickness of the bearing unit which is always stiffer than the embedding (upper and lower) mechanical units (Fig. 1a). The thickness of the bearing unit is at least a few meters and can reach several hundred meters (Fig. 1e). All types of carbonate and siliciclastic mechanical units in all types of tectonic settings can bear fracture corridors, which are prone to reactivation and fault localization (Souque et al., 2019). The particular fracture spacing distribution within the corridors clearly violates the general situation whereby in layered rocks, joint spacing typically tends to scale with bed thickness (Price, 1966; Ladeira and Price, 1981; Angelier et al., 1989; Price and Cosgrove, 1990; Narr and Suppe, 1991; Gross, 1993; Gross et al., 1995; Becker and Gross, 1996).

There is neither any synthesis describing the range of geometrical properties of fracture corridors (horizontal and vertical persistence, width, inter-corridor spacing), nor any attempt to define the geological or geomechanical conditions (depth, tectonic context) for their occurrence. The horizontal and vertical dimensions and the spacing between fracture corridor are difficult to document because complete sections of the bearing mechanical units are scarce (Fig. 1e). Most often, only a part

\footnotetext{
* Corresponding author. Beicip-Franlab, 232 Avenue Napoléon Bonaparte, 92502 Rueil-Malmaison Cedex, France.

E-mail address: ghislain.dejoussineau@beicip.com (G. de Joussineau).
} 
a
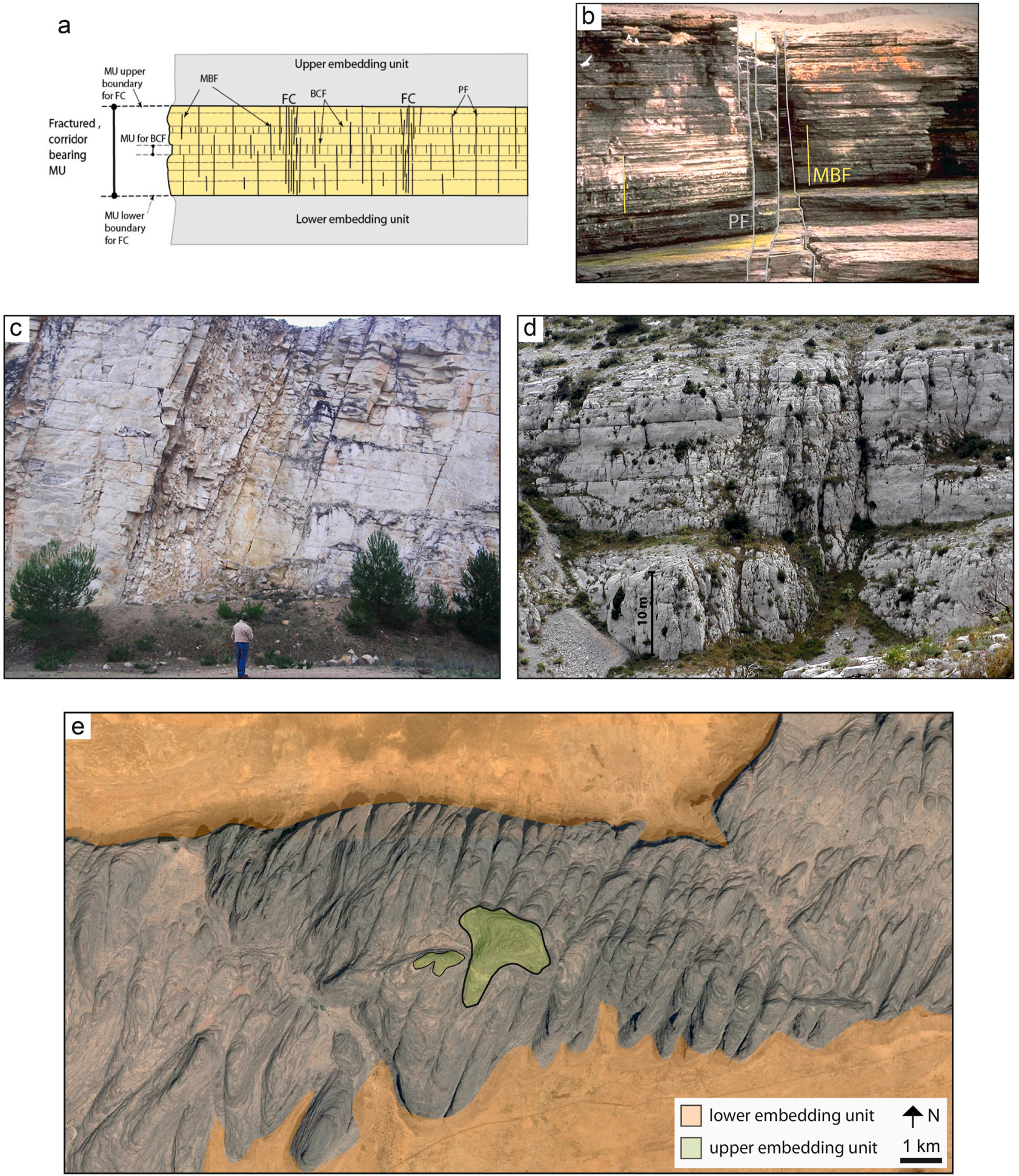

Fig. 1. Examples of fracture corridors of different sizes. a) Conceptual sketch of fracture corridors (FC) with details of constitutive and background fractures within a bearing competent mechanical unit (MU). Fracture corridors mainly contain Persistent Fractures (PF), that do not crosscut the entire mechanical unit. Multibed Fractures (MBF) of more limited persistence are present both inside and outside the corridors, whereas Bed Confined Fractures (BCF) are typically background fractures. b) Simple fracture corridor in a cliff in the old Red sandstones, Northern Scotland. MBF and PF are outlined. Scale is given by the bird (top left). c) Wide fracture corridor (slightly reactivated) in the Upper Cretaceous limestones of the Calvisson quarry, Southern France (see Bisdom et al., 2014). (d) Very wide fracture corridor in the Lower Cretaceous carbonates of Mount Puget, Southern France. Note the lateral continuity of the stratigraphic beds (absence of vertical offset). (e) Aerial (top) view of large systematic fracture corridors in the Late Precambrian to Cambrian sandstones and conglomerates of the Bandiagara plateau (Mali). Mechanical unit is ca. 400-m-thick. The upper and lower embedding units are outlined by green and orange transparent overlays, respectively. (For interpretation of the references to color in this figure legend, the reader is referred to the Web version of this article.) 
of the bearing unit is observable (e. g. Bisdom et al., 2014 and Fig. 1 b-d).

It is also important to note that no absolute threshold value of the ratio between the fracture spacing in corridors (s) and the thickness of the mechanical unit $(t)$ is given in existing literature to define a fracture corridor. This is because the clustered character of the fractures composing the corridors, which can be approached on a statistical basis (Marrett et al., 2017; Laubach et al., 2018), is relative and depends on the background fracture spacing distribution in the study area, i.e. on the local geological context. Nevertheless, in this paper, we consider that joints could form a fracture corridor when their $\mathrm{s} / \mathrm{t}$ ratio is less than 0.2 .

Fracture corridors are believed to have a considerable practical impact on production in fractured reservoirs, by forming drains for fluids or providing permeability enhancement and/or anisotropy (Fig. 2a; Cosentino et al., 2001; Bockel-Rebelle et al., 2004, 2005; Elrafie et al., 2008; Caetano et al., 2014). Drilling experience reveals their link to localized enhanced production (Hart et al., 2002), water breakthrough (local intrusion of water), and major drilling mud losses. They can also act as seal-bypass systems (Ogata et al., 2014) especially when some of their constitutive fractures connect adjacent reservoir units (throughgoing fracture zones, Fig. 1 in Gross and Eyal, 2007).

From the authors' experience acquired during specific research with oil companies, it is clear that two groups of fracture corridors can be found. A first group is associated (geometrically and genetically) with structural heterogeneities: extensional quadrants of faults (Martel, 1994; Laubach et al., 1995) and local flexures or shale lenses (Bazalgette and Petit, 2007; Bazalgette et al., 2010). These "localized" fracture corridors can conceptually be related to tensile stress concentration in the vicinity of heterogeneities (Petit and Mattauer, 1995). A second group includes regularly distributed "systematic" fracture corridors, which are observed in tabular or slightly to moderately folded domains (Fig. 1e). They are a particular and poorly understood aspect of jointing, and their fracture clustering mechanisms remain enigmatic. They are the subject of this paper.

Many mechanical modeling studies focusing on the development of joints and their spacing properties in layered rocks were carried out in the last decades. They demonstrate the key role of the position of preexisting fractures and their spacing on the stress state in fractured layers, hence on further fracture propagations (Pollard and Segall, 1987; Gross et al., 1995; Rabinovitch and Bahat, 1999; Bai and Pollard, 2000a, b; Bai et al., 2000a). Neither these studies nor more recent ones introducing the influence of the interfacial (inter-bed) friction (Ji et al., 1998; Schöpfer et al., 2011) or of a hydro-mechanical loading (overburden combined with internal fluid pressure, Li et al., 2012) could explain the development of fracture corridors. Only the 2D LEFM models of Olson (2004) with synchronously interacting lateral fracture propagations from randomly distributed flaws show that clustering can occur for very high values of the subcritical index, which relates the stress intensity factor to the crack propagation velocity. This clustering mechanism which occurs in a stable growth regime enables to produce series of fracture clusters separated by large distances.

Apart from the work by Li et al. (2012) where fractures are internally pressurized, all the previously mentioned studies investigate joint formation under conditions of crack normal tension or extension. This loading condition is not frequent in the Earth's subsurface. Even in extensional (normal fault) regimes, the principal stresses are all typically compressive at depth (see the stress measurements compiled in Engelder, 1993). Based on this observation, Bourne (2003) and de Joussineau and Petit (2007) investigate how stress conditions favorable for opening-mode fracture propagations could develop in elastic models tested under compressive loading conditions. Bourne (2003) shows that tensile stress could develop in multilayers under uniform remote compression if there is sufficient contrast in the elastic properties between the layers. de Joussineau and Petit (2007) show the same effect of elastic contrasts on tensile stress development in multilayered models containing pre-existing open fractures, still tested under crack-normal compression conditions. They also identify fracture interaction as a key parameter allowing the development of large areas of crack-normal tensile stress in the fractured layers when fractures are close to each other $(\mathrm{s} / \mathrm{t}$ ratio $<1)$.

In this paper, we extend this work further by investigating how
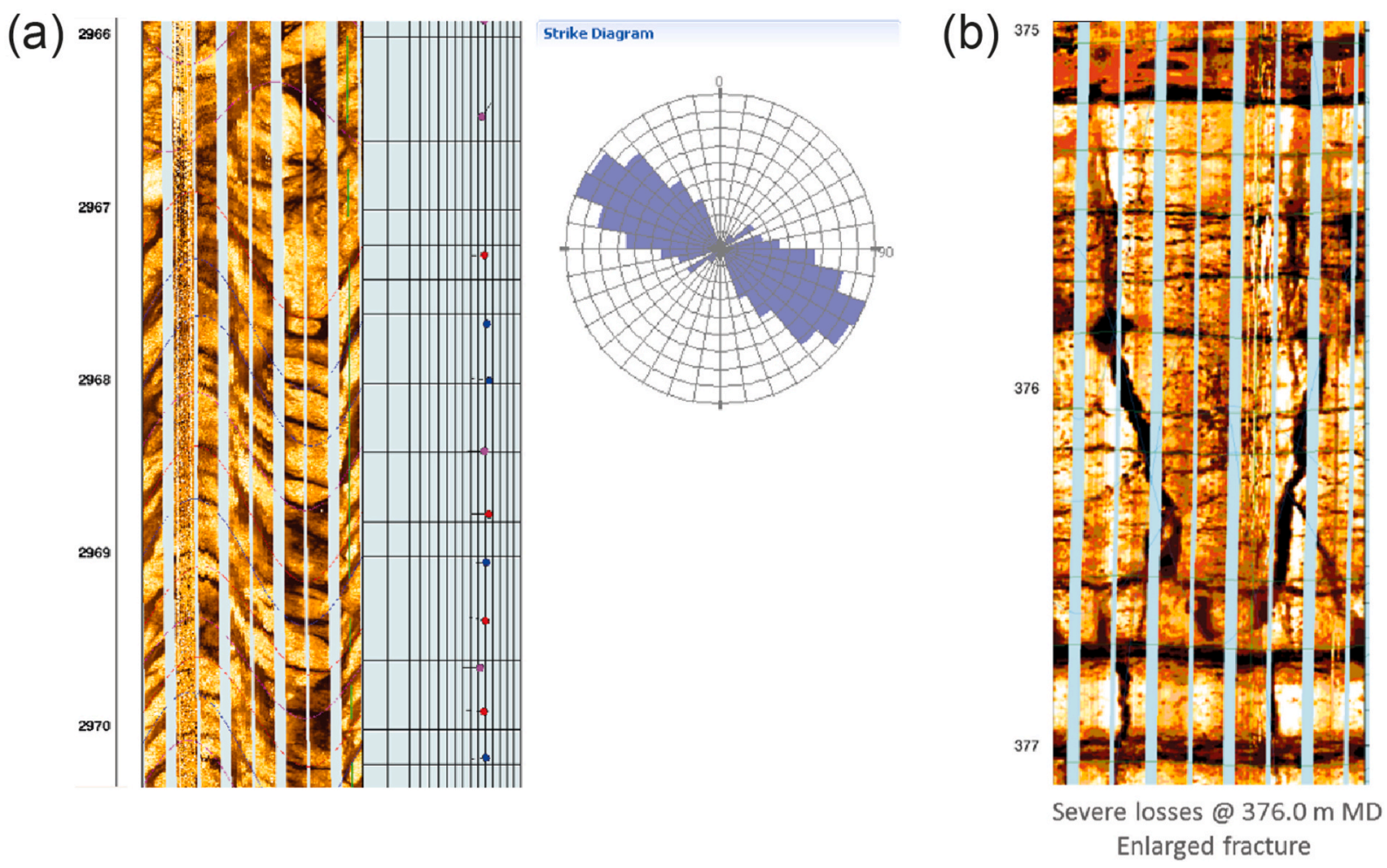

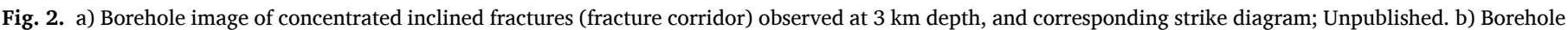
image of a large open fracture explaining severe mud losses (de Joussineau et al., 2016). 
fracture corridors could develop in 2D elastic finite element models containing open fractures and tested under plane strain conditions, with crack normal extension and compressive loading. In the first step, we identify favorable tensile stress situations promoting the formation of subsequent opening-mode fracturing in the fractured layers. In the second step, we test the modalities of the development of new fractures by numerical experiments using the fracture mechanics conditions for quasi-static fracture propagation. This allows the identification of three possible fracture clustering mechanisms.

The results obtained are used to propose a new model for the development of fracture corridors in layered rocks, with important consequences for the study of fluid flow in the subsurface.

\section{Numerical procedure}

\subsection{Models and boundary conditions}

In this study, we use the fracture code Franc 2D developed by the Cornell Fracture Group (Wawrzynek and Ingraffea, 1987). This finite element code has been used in many studies to compute stress fields (Fisher et al., 1995; Gross et al., 1995; Bai and Pollard, 2000a; Bai et al., 2000a; Engelder and Peacock, 2001; McConaughy and Engelder, 2001; de Joussineau and Petit, 2006, 2007), to calculate fracture apertures (Bai et al., 2000b; Bai and Pollard, 2001; de Joussineau and Petit, 2006) and evaluate stress intensity factors and energy release rates at the tips of fractures, allowing studying quasi-static fracture propagation from initial seeds (Bai and Pollard, 2000b; de Joussineau, 2003a,b; de Joussineau and Petit, 2004).

Our models are rectangles containing five bonded layers (Fig. 3a) with contrasts in the Young's modulus and a common Poisson's ratio

(a)

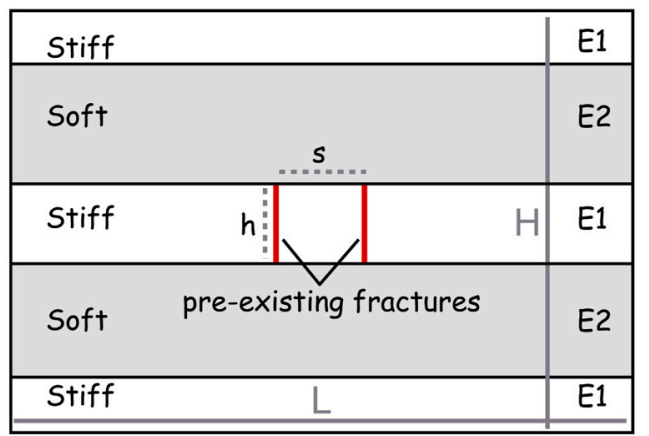

(b)

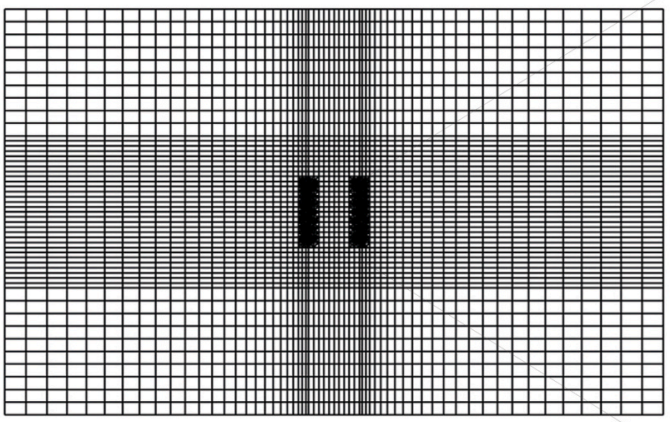

Fig. 3. (a) Geometry of the models containing a pair of open fractures in the central layer, with the distribution of soft and stiff materials indicated. (b) Quadratic mesh of the models with an enlargement showing the region around the fractures. equal to 0.25 , which is the value commonly used for modeling layered sedimentary rocks (Bai and Pollard, 2000b; Bai et al., 2000a,b; de Joussineau and Petit, 2007; Li et al., 2012). We choose not to vary the Poisson's ratio between the layers because this parameter shows little variations compared to the Young's modulus in sedimentary rocks (see values compiled in Atkinson, 1987). In the experiments, the Young's modulus of the stiff layers (high modulus) is fixed at 50 GPa (corresponding for instance to typical limestones) and the modulus of soft layers (low modulus) varies in order to cover a wide range of situations of elastic contrast. The central layer of the models is stiffer than the two adjacent ones and contains a pair of bed-bounded open fractures (Fig. 3a). This configuration resembles the typical situation of natural layered rocks where fractures develop in stiff layers (e.g. limestone, sandstone) and are absent or almost absent in soft layers (e.g. marl).

The thickness of the central fractured layer is fixed in the experiments and the thickness of the adjacent soft layers varies so that the effect of the soft/stiff ratio (ratio between the cumulative thickness of soft and stiff layers) can be tested.

The fractures in the models are composed of two adjacent planes with no condition of adhesion or friction. The initial fracture aperture is small (corresponding to millimeters if the dimensions of the models are meters). The dimensions and quadratic mesh (Fig. 3b) of the models were designed in an extensive preliminary study to have no effect on the stress field in the central fractured layer (de Joussineau, 2003a). In addition, sensitivity tests showed that reducing the number of fractures to two in the models impacted the stress and fracture aperture calculations by less than $2 \%$ compared to the situation of a large number of fractures, consistent with conclusions of previous investigators (Bai and Pollard, 2000b).

The displacement boundary conditions imposed to the models are shown in Fig. 4. They consist in two kinds of loading, a layer-parallel extension associated to a layer-perpendicular shortening (mixed boundary conditions; Fig. 4a) and a biaxial shortening (compressive boundary conditions; Fig. 4b), both corresponding to a plane strain situation. The vertical shortening and the horizontal extension or shortening are limited to $0.25 \%$ and $0.1 \%$, respectively, so that linear elasticity principles can apply (small deformation domain; Mandl, 1988).

\subsection{Stress measurements}

The stress considered in this study is the layer-parallel stress perpendicular to the fractures, $\sigma_{\mathrm{xx}}$. This is the stress controlling possible further propagations of Mode I fractures parallel to the pre-existing ones (de Joussineau and Petit, 2007), and the initiation and development of future fracture corridors in our study.

$\sigma_{\mathrm{xx}}$ was mapped in the models and maximum values of $\sigma_{\mathrm{xx}}$ in areas where it was a tensile stress were measured (values referred to as $\sigma_{\mathrm{xx}}$ ${ }_{\max }$ ), in order to identify favorable situations supporting further fracture propagations. Stress measurements were always made away from the tip region of the pre-existing fractures, where very small lobes of tensile stress developed during the experiments (fracture tip stress concentrations).

\subsection{Fracture propagation}

Once favorable tensile stress conditions (i.e. $\sigma_{\mathrm{xx}}=$ tensile stress) were identified in the models, tests of quasi-static fracture propagation were carried out using fracture seeds that have a length equal to 1 or $2.5 \%$ of the length of the pair of pre-existing fractures, depending on the situation investigated (i.e., seed length is 1 or $2.5 \mathrm{~cm}$ if model dimensions are metric- Fig. 5a). The position of the seeds was selected to test different situations of tensile stress in the fractured layer. The mesh along the seeds and in their tip regions was designed so that it had no effect on the calculation of the strain energy release rate, G, used to define the conditions of the fracture propagation. We preferred to use $G$ instead of the 
(a)

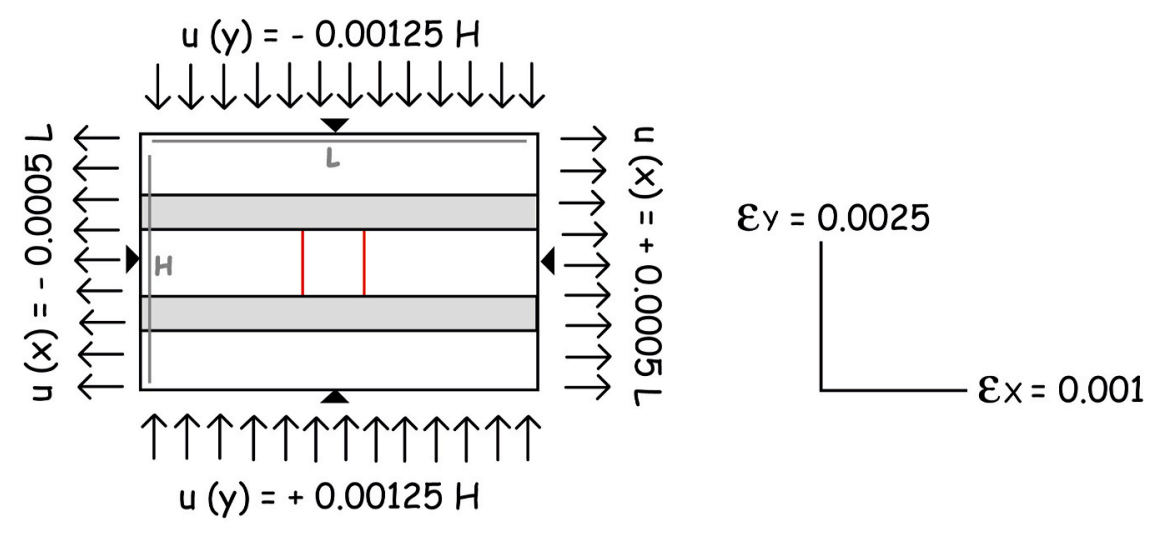

(b)

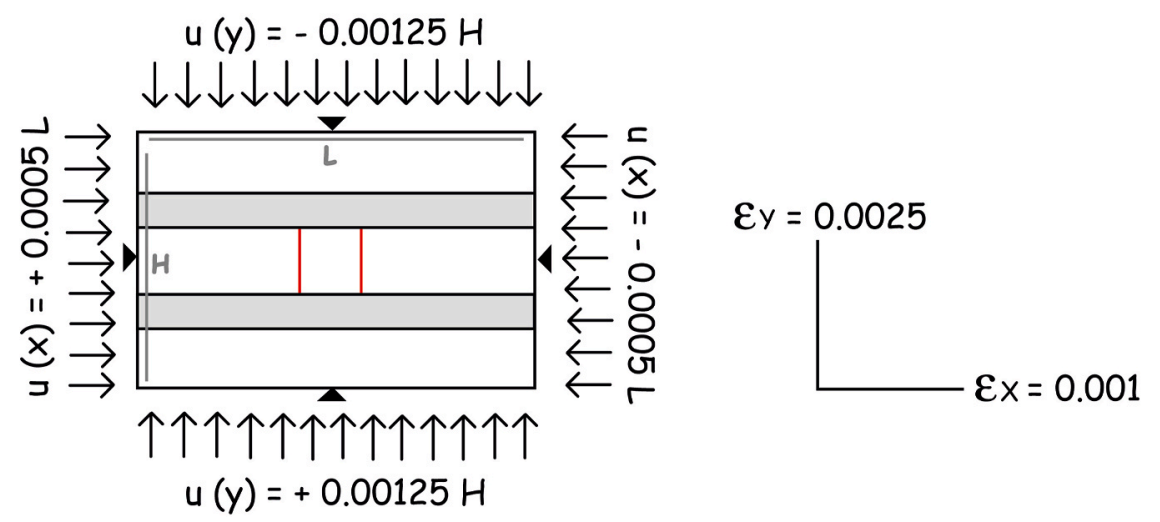

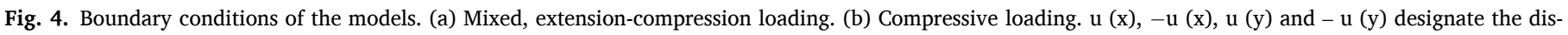

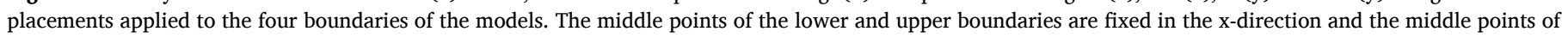
the left and right boundaries are fixed in the y-direction.

stress intensity factor, $\mathrm{K}$, because it is not possible to define accurately a threshold value for fracture propagation for $\mathrm{K}$ (equilibrium or threshold of propagation at $\mathrm{K}_{0} \neq 0$, propagation if $\mathrm{K}>\mathrm{K}_{0}$ ), whereas it is possible for $\mathrm{G}$, as detailed below. G was calculated using different methods (displacement correlation technique, J-integral and crack closure integral) and the one that yielded the most stable results, the crack closure integral, was selected and used in the study. This method has provided results very close to those of reference models under various boundary conditions (Rybicki and Kanninen, 1977) and is applicable to numerous 2D problems if tests concerning the mesh refinement at the tips of the fracture seeds are realized (Raju, 1987).

Quasi-static fracture propagation was carried out in favorable regions of the models, i.e. regions where $\sigma_{\mathrm{xx}}$ was a tensile stress. The Griffith criterion (Griffith, 1920) was used for fracture propagation, such that $\mathrm{G}>2 \gamma_{\mathrm{F}}$, where $\gamma_{\mathrm{F}}$ is the surface energy, i.e. the energy needed to create, in a reversible and isothermal manner, a new fracture surface in the solid (Barquins 1985). $\gamma_{\mathrm{F}}$ is available in literature for most of rock minerals, making it possible to define a reliable fracture propagation criterion. In this study, $\gamma_{\mathrm{F}}$ was set to $0.35 \mathrm{~J} / \mathrm{m}^{2}$, i.e. the equilibrium (threshold of propagation) value $\mathrm{G}_{\mathrm{o}}=2 \gamma_{\mathrm{F}}=0.7 \mathrm{~J} / \mathrm{m}^{2}$, consistent with values obtained for classical natural sedimentary minerals (Atkinson, 1987).

Fracture seeds were propagated in Mode I in several consecutive steps (Fig. 5b), as long as the condition $\mathrm{G}>2 \gamma_{\mathrm{F}}$ was satisfied (Fig. 5c). As soon as the fracture propagation resulted in a situation where $G<2 \gamma_{\mathrm{F}}$ ( $G_{0}=2 \gamma_{F}$ is the equilibrium state), we went back to the previous stage of fracture propagation and tested a shorter increment of propagation. This allowed the evaluation of the maximum length reached by the propagating fracture seed in the most accurate way possible.

\section{Results}

\subsection{Stress domains}

We first present the results obtained in terms of stress $\left(\sigma_{\mathrm{xx}}\right)$ computation. A series of tests was carried out in order to study the impact of the different model parameters (pre-existing fracture spacing, elastic contrast between the soft and stiff layers and soft/stiff ratio) on the distribution and levels of tensile stress in the fractured layer. The ranges of values for each tested parameter, allowing coverage of a wide range of sedimentary situations, are the following:

- Spacing (s) between the pre-existing fractures: $\mathrm{s}=0.5 \mathrm{~h}, \mathrm{~s}=\mathrm{h}$, and $\mathrm{s}$ $=1.5 \mathrm{~h}$ (h being the thickness of the fractured layer);

- Elastic contrast (E1/E2) between the soft and stiff layers: E1/E2 = 2 $(\mathrm{E} 1=50 \mathrm{GPa}$ and $\mathrm{E} 2=25 \mathrm{GPa}), \mathrm{E} 1 / \mathrm{E} 2=10(\mathrm{E} 1=50 \mathrm{GPa}$ and $\mathrm{E} 2=$ $5 \mathrm{GPa})$, and $\mathrm{E} 1 / \mathrm{E} 2=50(\mathrm{E} 1=50 \mathrm{GPa}$ and $\mathrm{E} 2=1 \mathrm{GPa})$;

- Soft/stiff thickness ratio: soft/stiff $=0.025$, soft/stiff $=0.11$, soft/ stiff $=0.33$, and soft/stiff $=1$; these values correspond respectively to a thickness of the soft layers equal to $0.1 \mathrm{~h}, 0.4 \mathrm{~h}, \mathrm{~h}$, and $2 \mathrm{~h}$ ).

Both types of loading conditions result in the development of tensile stress in the models. The situation of mixed boundary conditions yields results that compare well with the ones obtained by Bai and Pollard (2000a,b), whereas the development of tensile stress in the situation of compressive boundary conditions is fully consistent with what was already documented by de Joussineau and Petit (2007).

In the case of mixed boundary conditions, $\sigma_{\mathrm{xx}}$ is a tensile stress in two particular zones of the models: (1) at the interfaces between the central stiff and underlying/overlying soft layers and (2) in the center of the 
(a)
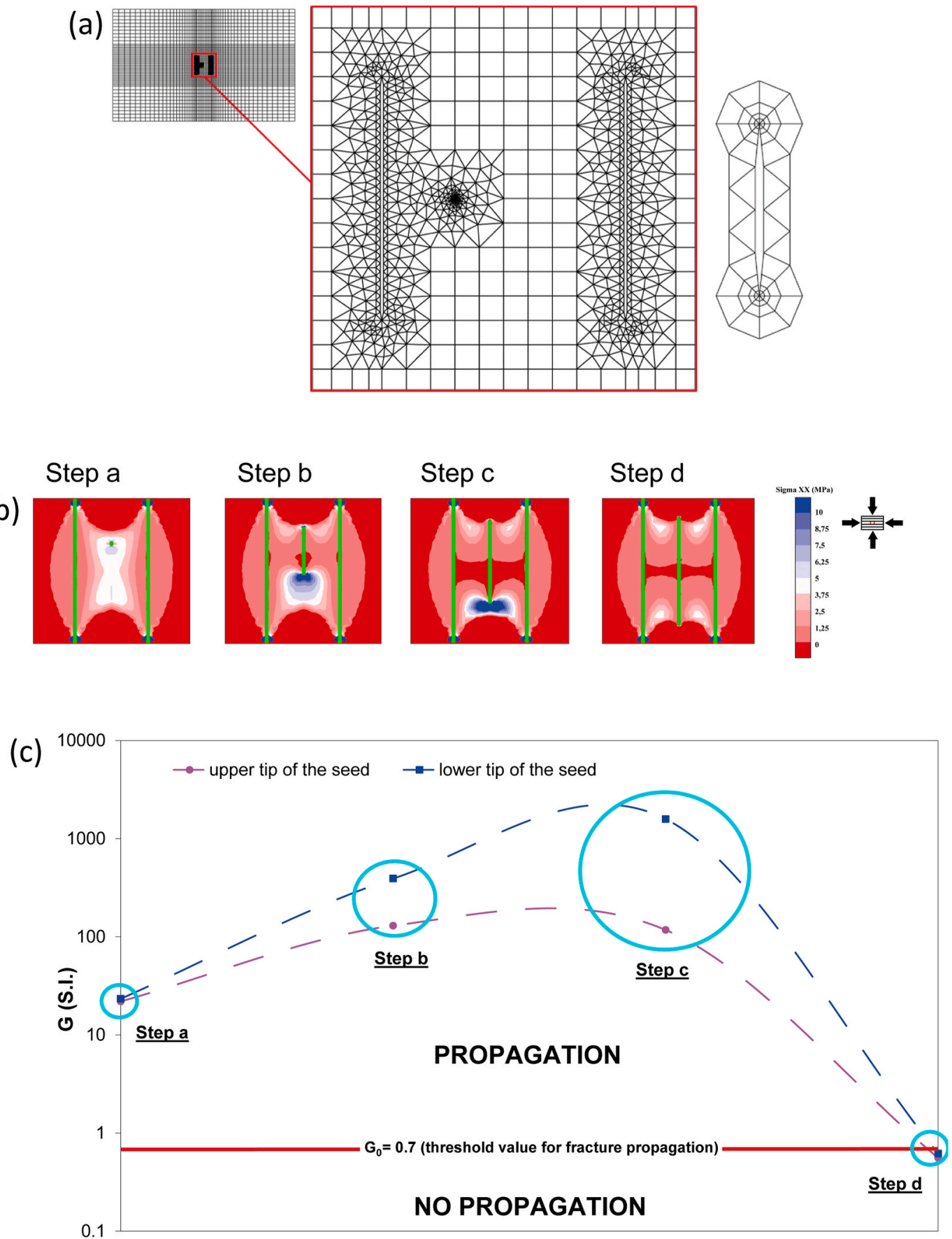

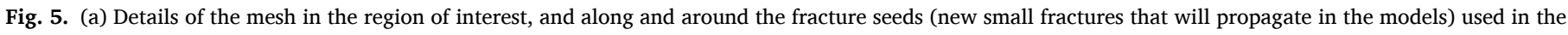

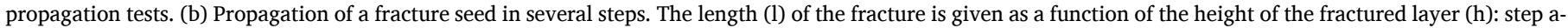

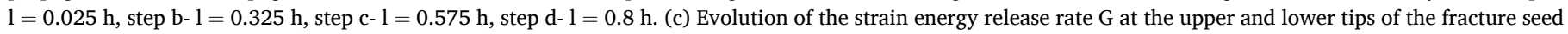
during its propagation (at steps a, b, c and d).

central stiff layer, if the fracture spacing is typically larger that the thickness of the fractured layer (Fig. 6). The tensile stress confined near the interfaces in the case of a small fracture spacing (Fig. 6a) spreads towards the center of the fractured layer when the fracture spacing increases (Fig. 6b and c). These results agree with the stress transition proposed by Bai and Pollard (2000b) and Bai et al. (2000a) and suggest that, even if the tensile stress values are the highest for a low fracture spacing (Figs. 6a and 8a), the tensile stress distributions are more favorable to the initiation and propagation of new fractures in the region of interest (i.e. the region between the pre-existing fractures) for larger pre-existing fracture spacings. In addition, the stress distribution in
Fig. 6 suggests that new fractures will tend to appear near the interfaces between the fractured layer and the adjacent softer layers, and will typically propagate towards the center of the fractured layer.

In the case of compressive conditions, the situation is opposite. Tensile stress develops in the two following zones of the models: (1) in lobes (halos) centered on the fractures and (2) in the center of the central stiff layer, if the fracture spacing is typically equal to or smaller than the thickness of the fractured layer (coalescence of lobes of tensile stress) (Fig. 7). The tensile stress is exclusively located near the pre-existing fractures in the case of a large fracture spacing (tension halo, Fig. 7c) but occupies the whole central part of the region of interest for fracture 
(a)

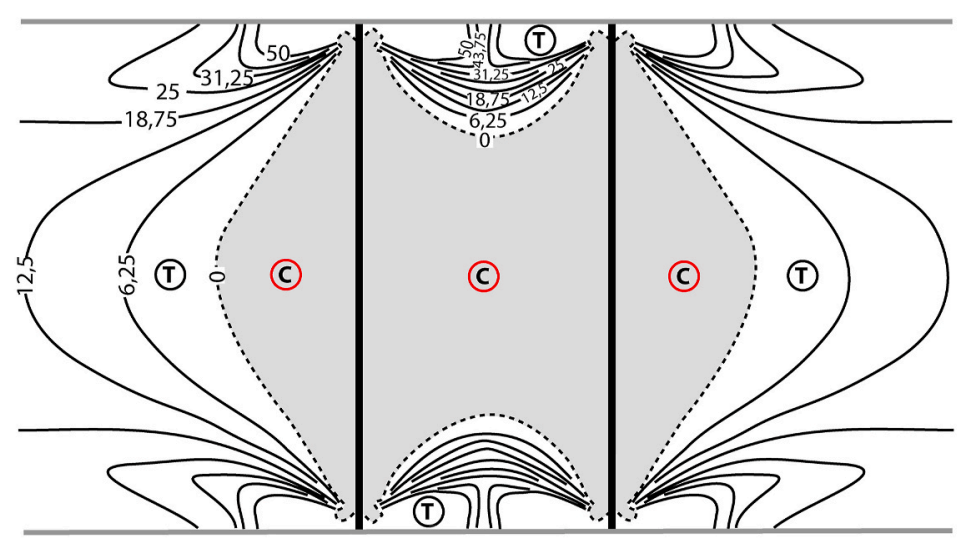

(b)

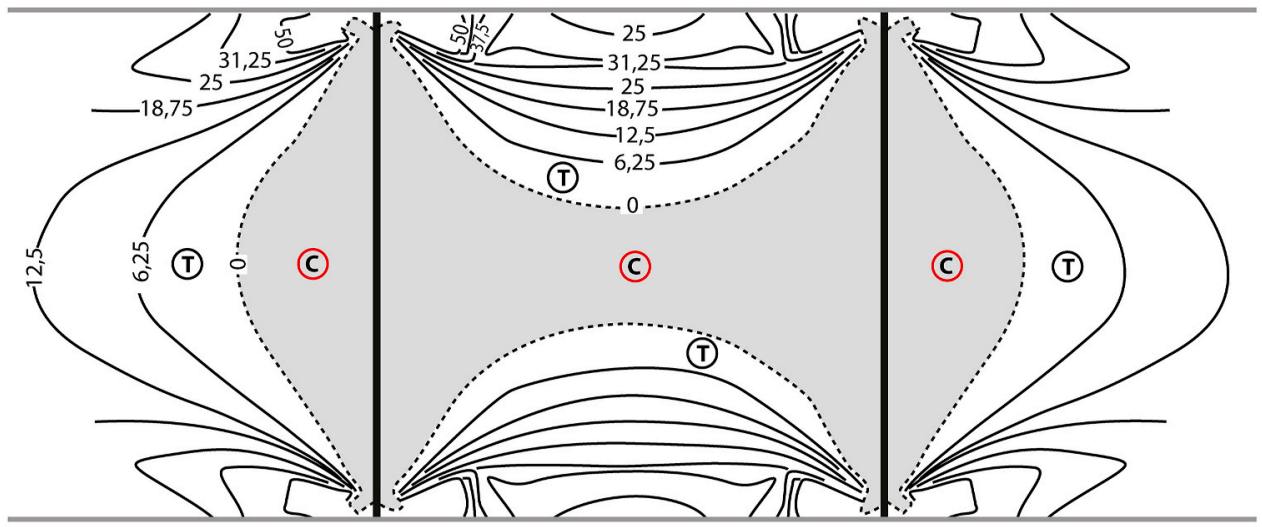

(c)

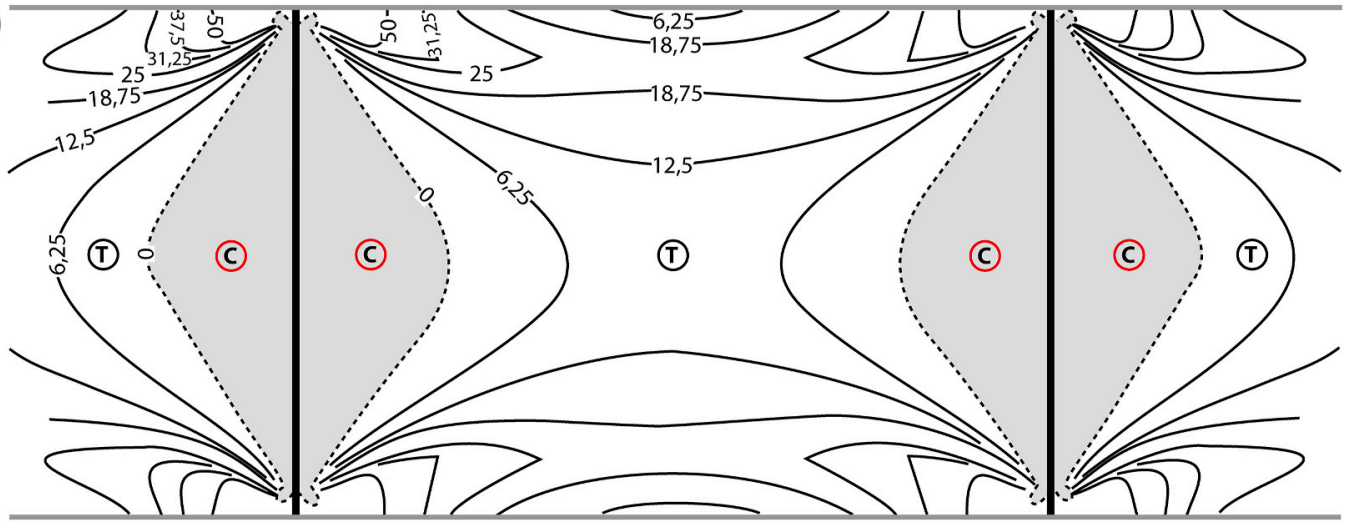

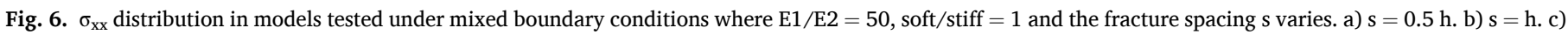

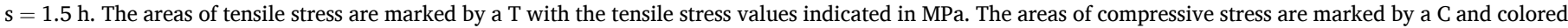
in grey. The limits between the tensile and compressive areas are shown by broken contours (same convention used in next comparable figures).

spacings equal to or lower than the layer thickness (Fig. 7a and b). Accordingly, the tensile stress distributions are more favorable to the initiation and propagation of new fractures in the region of interest for smaller pre-existing fracture spacings. The results of Fig. 7 also suggest that under compressive conditions, new fractures will appear near the center of the fractured layer and will propagate towards its interfaces with the adjacent softer layers.

Fig. 8 presents the maximum tensile stress values obtained for each model tested (the different colors show the different elastic contrasts and the different symbols show the different soft/stiff ratios; some data points are superimposed and marked by arrows in the figure). Fig. 8 shows that the effect of fracture spacing, already commented upon in relation to Figs. 6 and 7, is very important. The tensile stress levels reached in the zone of interest typically decrease with an increasing fracture spacing. This is particularly true for compressive conditions, where significant tensile stress only develops in the central region of the fractured layer by the coalescence of the tensile lobes centered on the pre-existing fractures when the fracture spacing decreases (see also de Joussineau and Petit, 2007). The tensile stress levels, moderate in the isolated tensile lobes, strongly increase where the lobes coalesce. The impact of fracture spacing on tensile stress levels, even if globally similar, is less contrasted for the mixed boundary conditions.

Fig. 8 also shows that the elastic contrast has a positive effect on tensile stress levels in the region of interest. As already documented by previous authors (Bai and Pollard, 2000a; Bai et al., 2000a; Bourne, 2003; de Joussineau and Petit, 2007), larger elastic contrasts between the stiff and soft layers result in larger tensile stress levels. However, this parameter has a much less important impact on the development of tensile stress in the fractured layers compared with the fracture spacing. Indeed, for given values of the fracture spacing and soft/stiff ratio, varying the elastic contrast does not modify drastically the distributions of areas of tensile and compressive stress in the models (see illustration 
(a)
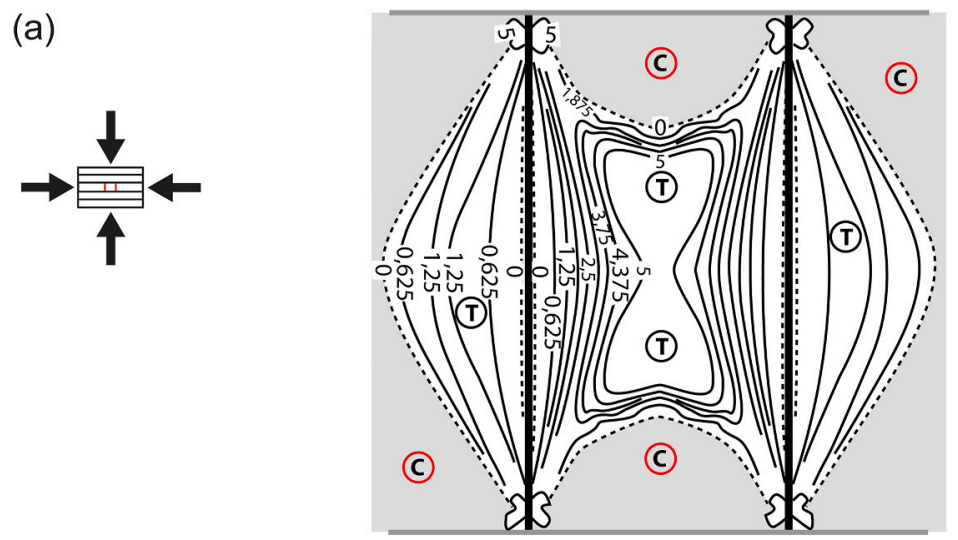

(b)

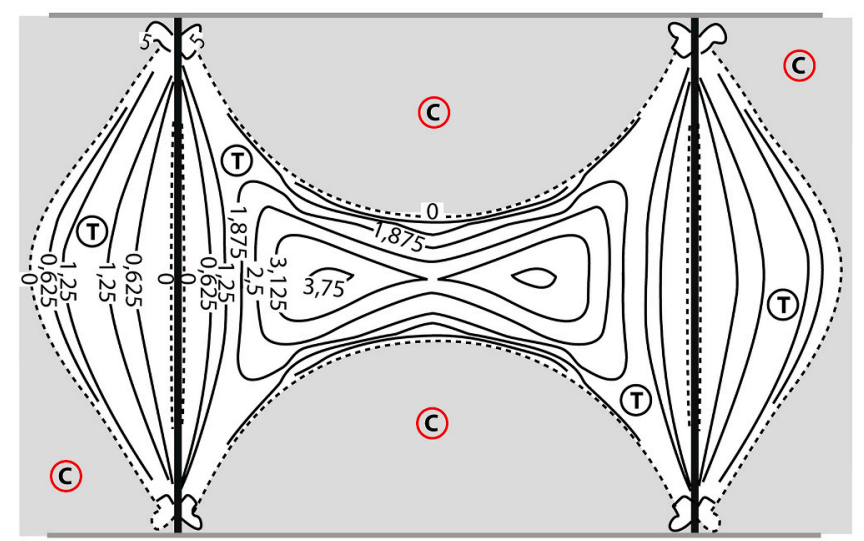

(c)

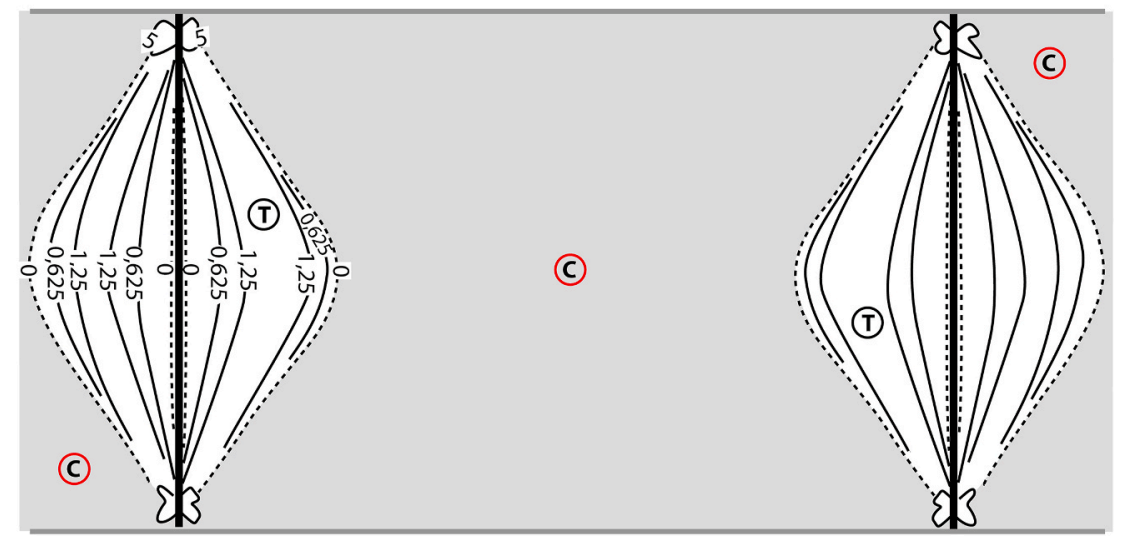

Fig. 7. $\sigma_{\mathrm{xx}}$ distribution in models tested under compressive boundary conditions where $\mathrm{E} 1 / \mathrm{E} 2=50$, soft/stiff $=1$ and the fracture spacing $\mathrm{s}$ varies. a) $\mathrm{s}=0.5 \mathrm{~h}$. b) $\mathrm{s}$ $=$ h. c) $\mathrm{s}=1.5 \mathrm{~h}$.

for mixed boundary conditions in Fig. 9).

Finally, the effect of the soft/stiff ratio on $\sigma_{\mathrm{xx}}$ distribution in the region of interest is very similar to that of the elastic contrast. A bigger soft/stiff ratio (i.e. thicker soft layers) results in more tensile stress and slightly larger tensile stress areas in the region of interest of the models, but without changing fundamentally the stress distribution in the region of interest for given values of the fracture spacing and elastic contrast (see illustration for compressive boundary conditions in Fig. 10).

\subsection{Fracture propagations and clustering mechanisms}

In this section, we present the results of the fracture propagation tests carried out and identify three mechanisms promoting the development of fracture corridors in the fractured layer.

The fracture propagation tests were carried out for the two types of boundary conditions, for the three different fracture spacing configurations ( $s=0.5 \mathrm{~h}, \mathrm{~s}=\mathrm{h}, \mathrm{s}=1.5 \mathrm{~h}$ ). For each fracture spacing configuration, propagation tests were done for a favorable case (soft/ stiff ratio and elastic contrast values resulting in well-developed tensile stress and high tensile stress values) and a less favorable case (moderate tensile stress, small tensile stress areas), in order to capture the range of fracture propagation situations.

The figures presenting the fracture propagation tests (Figs. 11, 14 and 16) are composed of five parts labelled 1, 2, 3, 4 and 5. Their first two parts (Parts 1 and 2) present the fracture propagation tests carried out, with the position and final length (L) of fractures that propagated (in red) in between the pre-existing fracture pair (in black). The black dots on the new fractures indicate the position of the fracture seeds used for the propagation tests, and the timing of the different fracture propagations is indicated. Time $t_{\mathrm{o}}$ indicates that fractures were propagated alone (independently) in the model, only in the presence of the preexisting fractures bounding the region of interest. For this situation, 
(a)

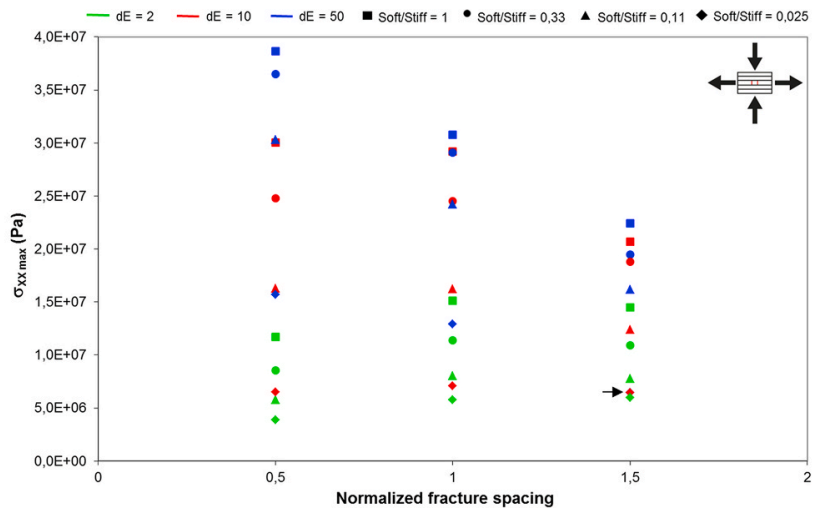

(b)

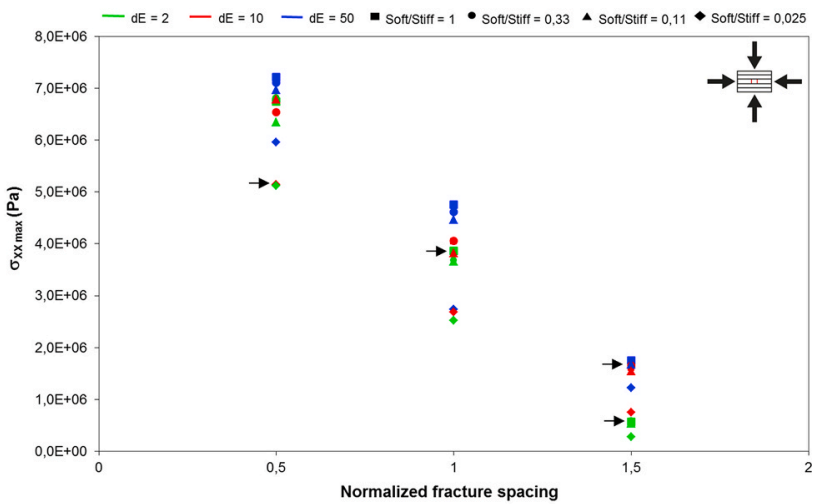

Fig. 8. Maximum tensile stress $\left(\sigma_{x x} \max \right)$ levels reached in the region of interest (between the fractures) for different model configurations. The fracture spacing is plotted in abscissa, the elastic contrast $\mathrm{dE}$ is color-coded and the soft/stiff ratio is indicated by different symbols. Arrows point at superimposed data points. (a) Mixed boundary conditions. (b) Compressive boundary conditions. (For interpretation of the references to color in this figure legend, the reader is referred to the Web version of this article.)

(a)

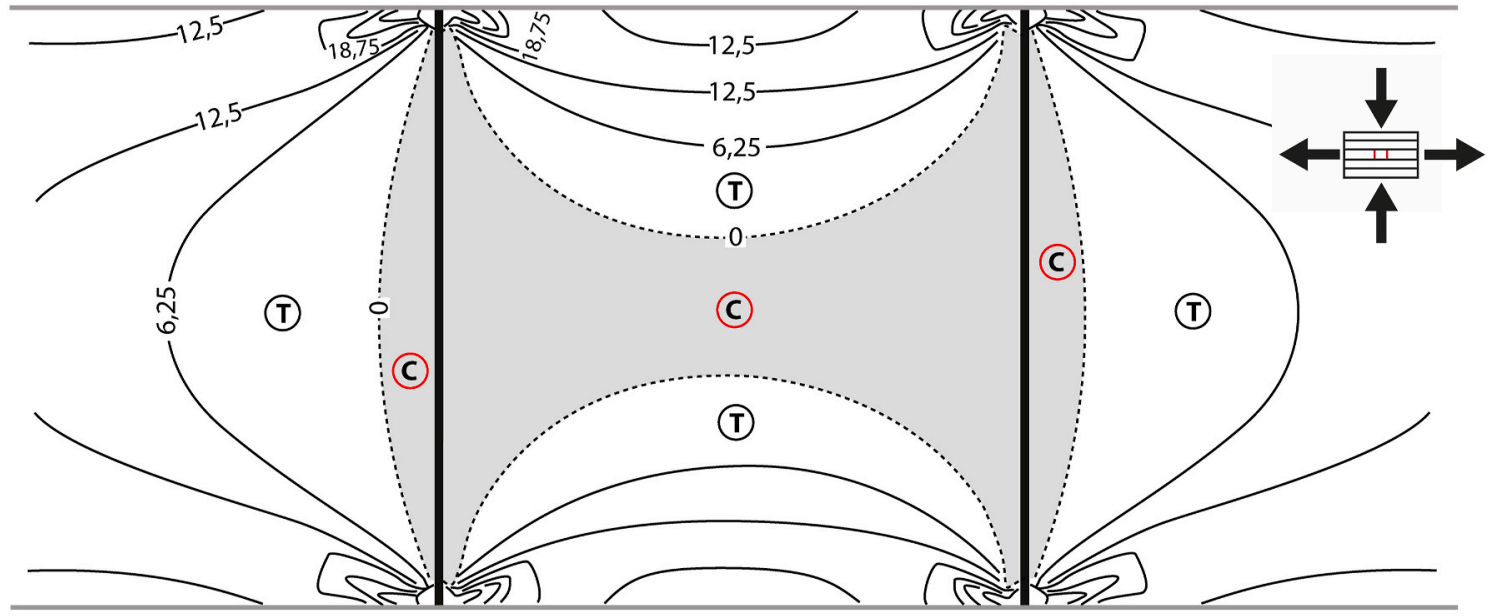

(b)

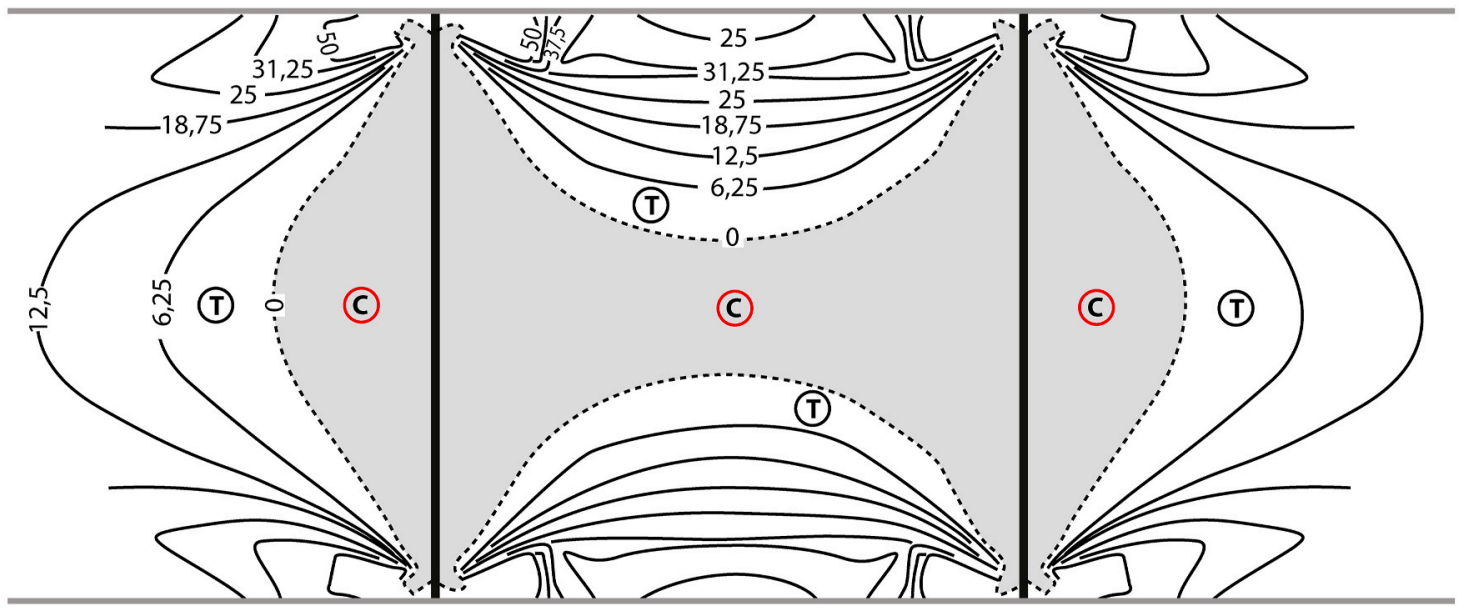

Fig. 9. Examples of stress distribution in models tested under mixed boundary conditions and where soft/stiff $=1, \mathrm{~s}=\mathrm{h}$ and E1/E2 varies. a) E1/E2 $=2$. (b) E1/E2 $=50$.

the figures may show a synthesis of several independent propagation tests (example of Fig. 11d Part 1: three distinct tests are shown), in order to indicate the final length reached by a propagating fracture depending on its position in the region of interest.

Other times mentioned in the figures are for situations of simultaneous or consecutive propagations. In this case, if all fractures propagated at time $t_{1}$, they all propagated simultaneously with mechanical interactions (example of Fig. 11a Part 2). Otherwise, if several times are indicated, the first fracture was entirely propagated at time $t_{1}$ and the subsequent ones were propagated at times $t_{2}$ and $t_{3}$ (if applicable) in a stress field modified by the earlier propagation stages (example of Fig. 11d Part 2).

Part 3 of the figures presents the initial stress field in the models, prior to any fracture propagation. Finally, Parts 4 and 5 of the figures 


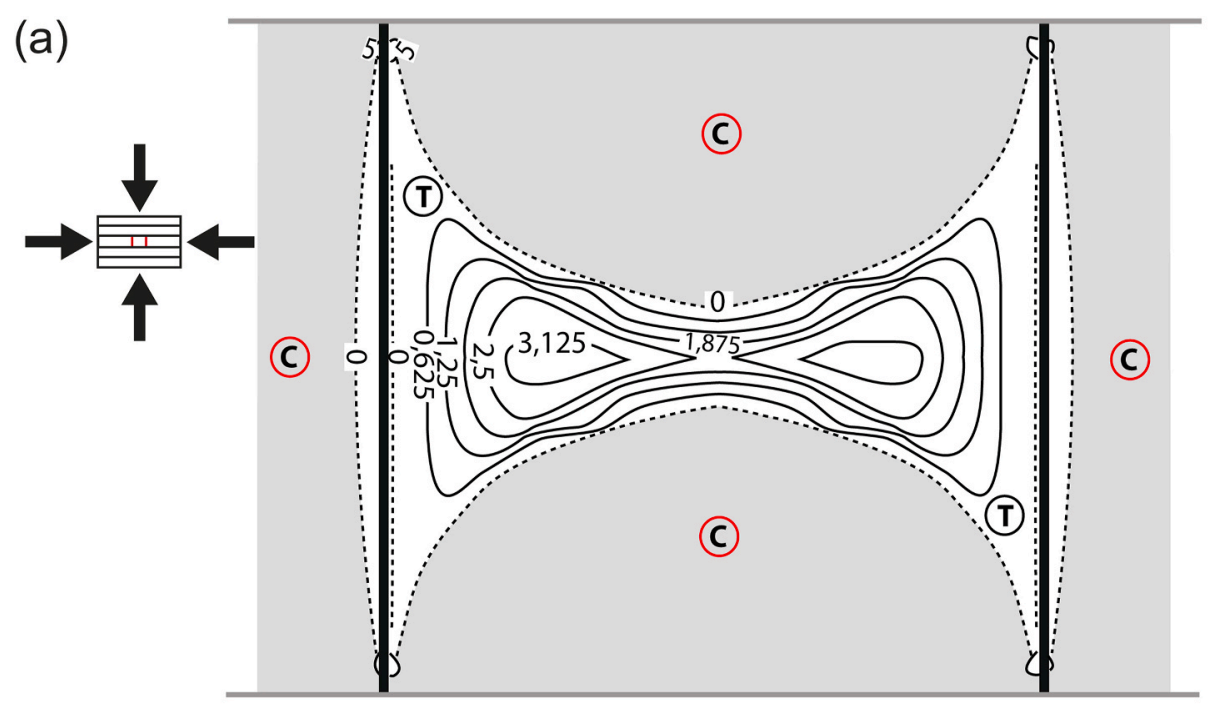

(b)

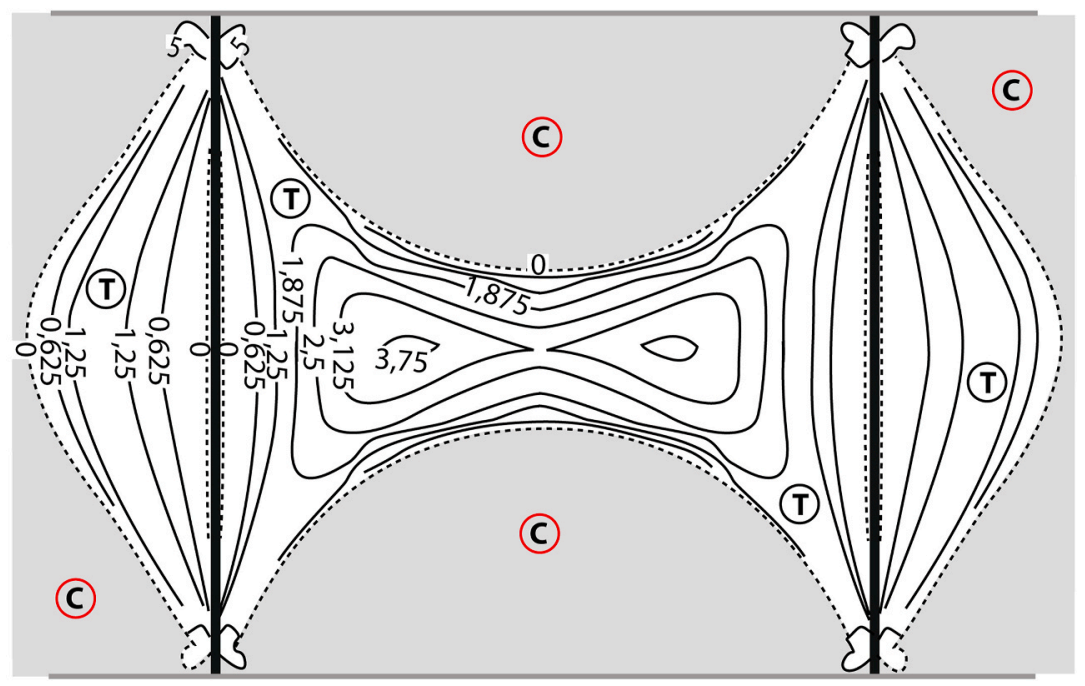

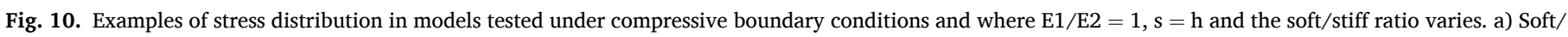
stiff $=0.025$. b) Soft/stiff $=1$.

present the typical, conceptual fracture arrangements that could be obtained in the model configurations considered (fracture patterns obtained depending on the location of fracture seeds, their timing of propagation (indicated) and the final fracture lengths obtained).

\subsubsection{Mixed boundary conditions}

For the mixed boundary conditions, the fracture seeds are located at or very near the interfaces with the adjacent soft layers, corresponding to a fracture initiation at the layer interfaces and a propagation towards the center of the layer. In the situation where $s=0.5 \mathrm{~h}$, because the tensile stress in the region of interest is limited to small lobes at the interfaces separated by a large zone of compressive stress, the fracture propagations are always partial, meaning that the propagating seeds never manage to crosscut the fractured layer fully (Fig. 11a and b Parts 1-2). No clear tendency to fracture clustering is detected (Fig. $11 \mathrm{a}$ and $\mathrm{b}$ Parts 4-5). However, small final fracture spacings $(\sim 0.1-0.15 \mathrm{~h})$ can be obtained with fracture propagations reaching up to $70 \%$ of the height of the fractured layer in the most favorable case (Fig. 11a Part 2).

This situation compares well with the natural example of Fig. 12, taken from the Lodève basin in Southern France. This figure shows a joint that initiated at the interface between a thin sandstone bed and a thicker pelite layer and propagated into the pelite bed without crosscutting it completely. This fracture is part of a dense family thought to have formed during the exhumation of the basin (de Joussineau et al., 2005), in a normal fault regime which may be comparable with the mixed boundary conditions of our models.

In the situation where $s=h$, the propagating seeds manage to crosscut the fractured layer entirely when located halfway between the pre-existing fractures (Fig. 14a and $\mathrm{b}$ Part 1; situation leading back to the conditions of Fig. 11a and b). Other propagations at a closer distance from a pre-existing fracture remain partial and no obvious fracture clustering mechanism could be identified (Fig. 14a and b Parts 2-4-5). Finally, when $s=1.5 \mathrm{~h}$, large areas and significant levels of tensile stress exist in the region of interest and complete fracture propagations can be obtained at a small distance from the pre-existing fractures $(0.15$ h, Fig. 16a Part 2). A seed located near a pre-existing fracture will totally crosscut the fractured layer if it is alone (case of Fig. 16a Part 2), although a comparable seed will only propagate partially when another seed located next to it in the region of interest propagates simultaneously or in a previous step (Fig. 16a Part 1, fracture example with $\mathrm{L}=$ $0.65 \mathrm{~h})$.

The propagation situations described may allow small fracture corridors formed by a few fractures to develop, if seeds located in the zone of maximum tensile stress situated close to the pre-existing fracture at the layer interface propagate first, before any other in the vicinity (see encircled zone in Parts 4-5 of Fig. 16a). We define this mechanism as the 


\begin{tabular}{|c|c|c|}
\hline EXPERIMENTS CARRIED OUT & $\begin{array}{c}\text { INITIAL } \\
\text { STRESS FIELD }\end{array}$ & $\begin{array}{c}\text { CONCEPTUAL } \\
\text { FRACTURE ARRANGEMENTS }\end{array}$ \\
\hline
\end{tabular}

(a)

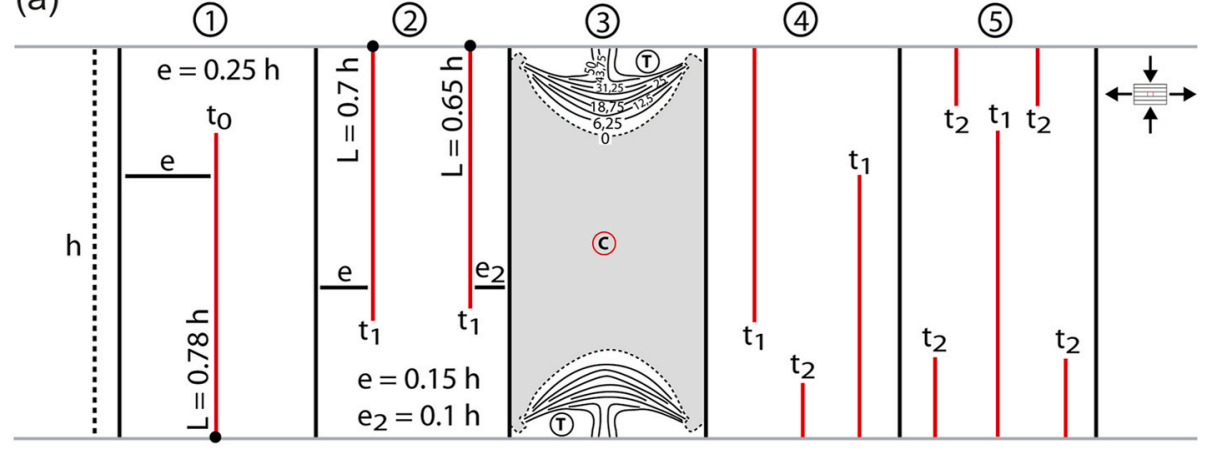

Fig. 11. Fracture propagation tests carried out in the case where $\mathrm{s}=0.5 \mathrm{~h}$, for $\operatorname{mixed}(\mathrm{a}, \mathrm{b})$ and compressive (c, d) boundary conditions. 1 \& 2: Distribution and maximum length reached by new fractures (red) propagated between the pre-existing ones (black). The black dots indicate the initial location of the fracture seeds and the timings of fracture propagations are indicated. 3: Initial stress field in the region of interest. 4 \& 5: Conceptual fracture arrangements inferred from the tests in $1 \& 2$ (same convention used in next comparable figures). (a) $\mathrm{E} 1 / \mathrm{E} 2=50$ and soft/stiff $=1$. (b) $\mathrm{E} 1 / \mathrm{E} 2=2$ and soft/stiff $=0.025$. (c) $\mathrm{E} 1 / \mathrm{E} 2=10$ and soft $/$ stiff $=$ 0.33. (d) $\mathrm{E} 1 / \mathrm{E} 2=50$ and soft/stiff $=0.025$. (For interpretation of the references to color in this figure legend, the reader is referred to the Web version of this article.)

(b)

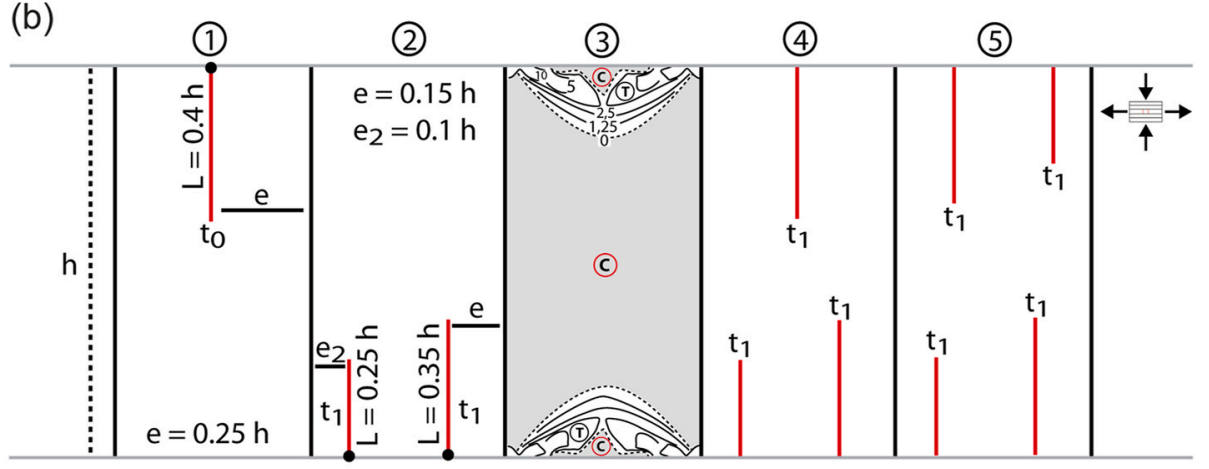

(c)

(1) (2)

(3)

(4)

(5)

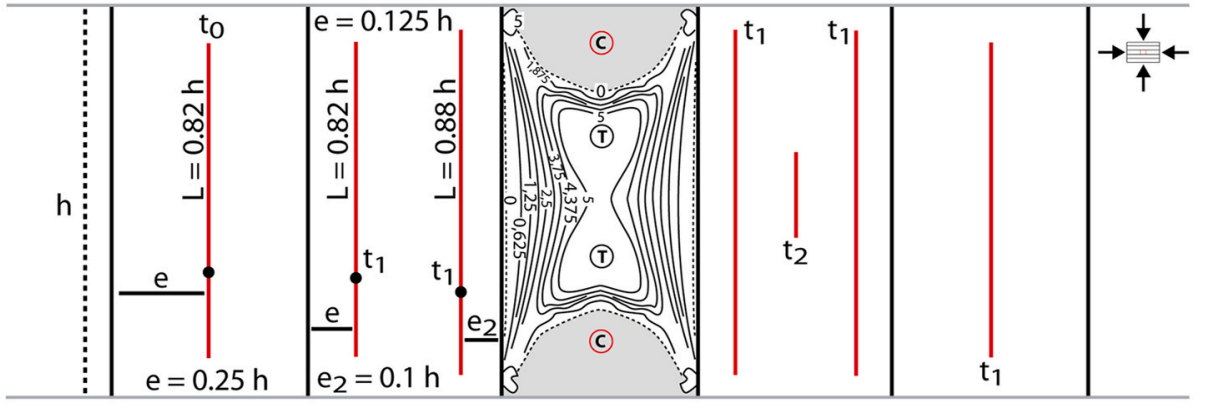

(d)

(1)

(2)

(3)

(4)

(5)

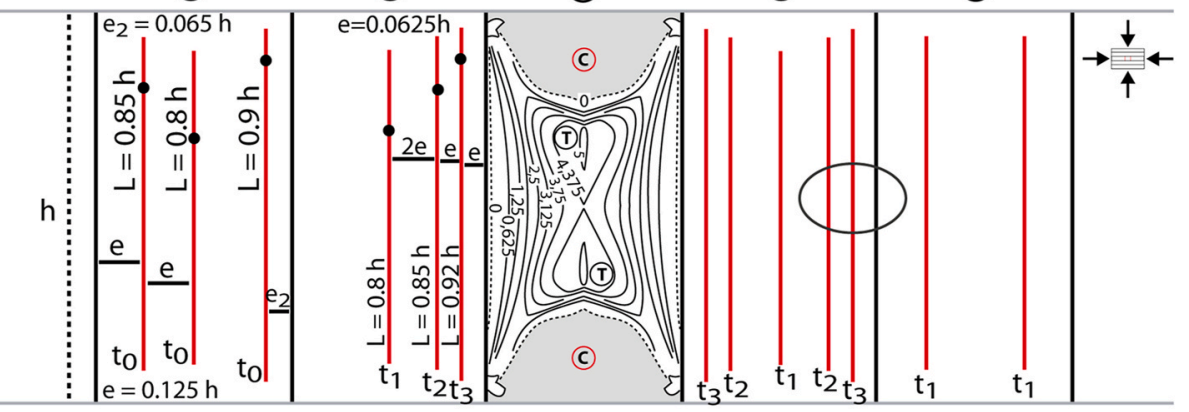

first come first served clustering mechanism.

\subsubsection{Compressive boundary conditions}

For the compressive boundary conditions, the fracture seeds were located within the fractured layer, corresponding to a fracture initiation near the center of the layer and a propagation towards its interfaces with the adjacent soft layers.
In the situation where $\mathrm{s}=0.5 \mathrm{~h}$, a continuous zone with significant levels of tensile stress exists in the region of interest (Fig. 11c and d Part 3). This situation supports the propagation of new fractures over significant distances ( $\mathrm{L} \geq 0.8 \mathrm{~h}$ ) with very small final fracture spacings (Fig. 11c Part 2 and 11d Parts 1-2). The fracture seeds located closest to the pre-existing fractures reach the greatest final lengths (see comparison between seeds in Fig. 11c Part 2 for instance). This situation allows 


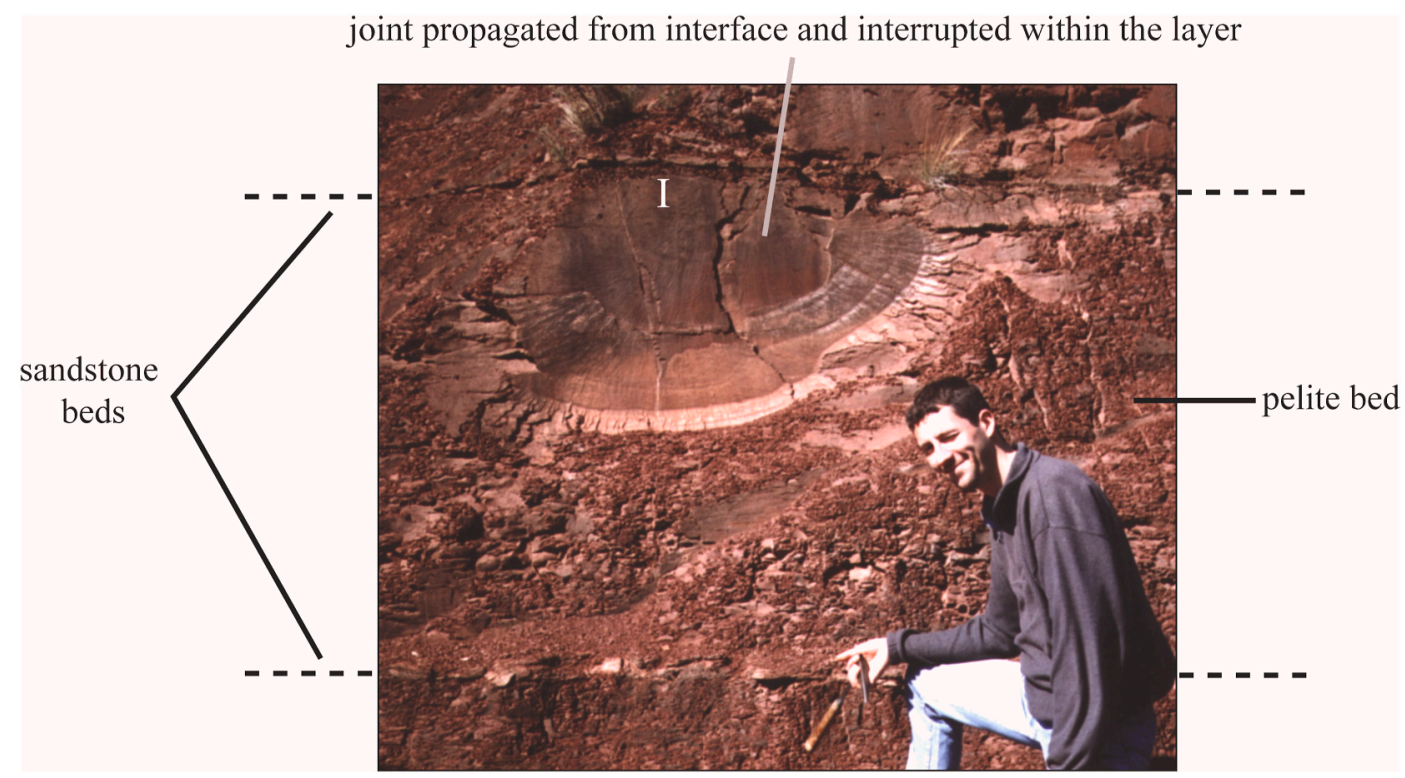

Fig. 12. Joint initiated at the interface between a pelite bed and a sandstone bed (initiation point noted by a I on the figure) and whose propagation through the pelite bed is incomplete (example from the Lodève basin, Southern France).
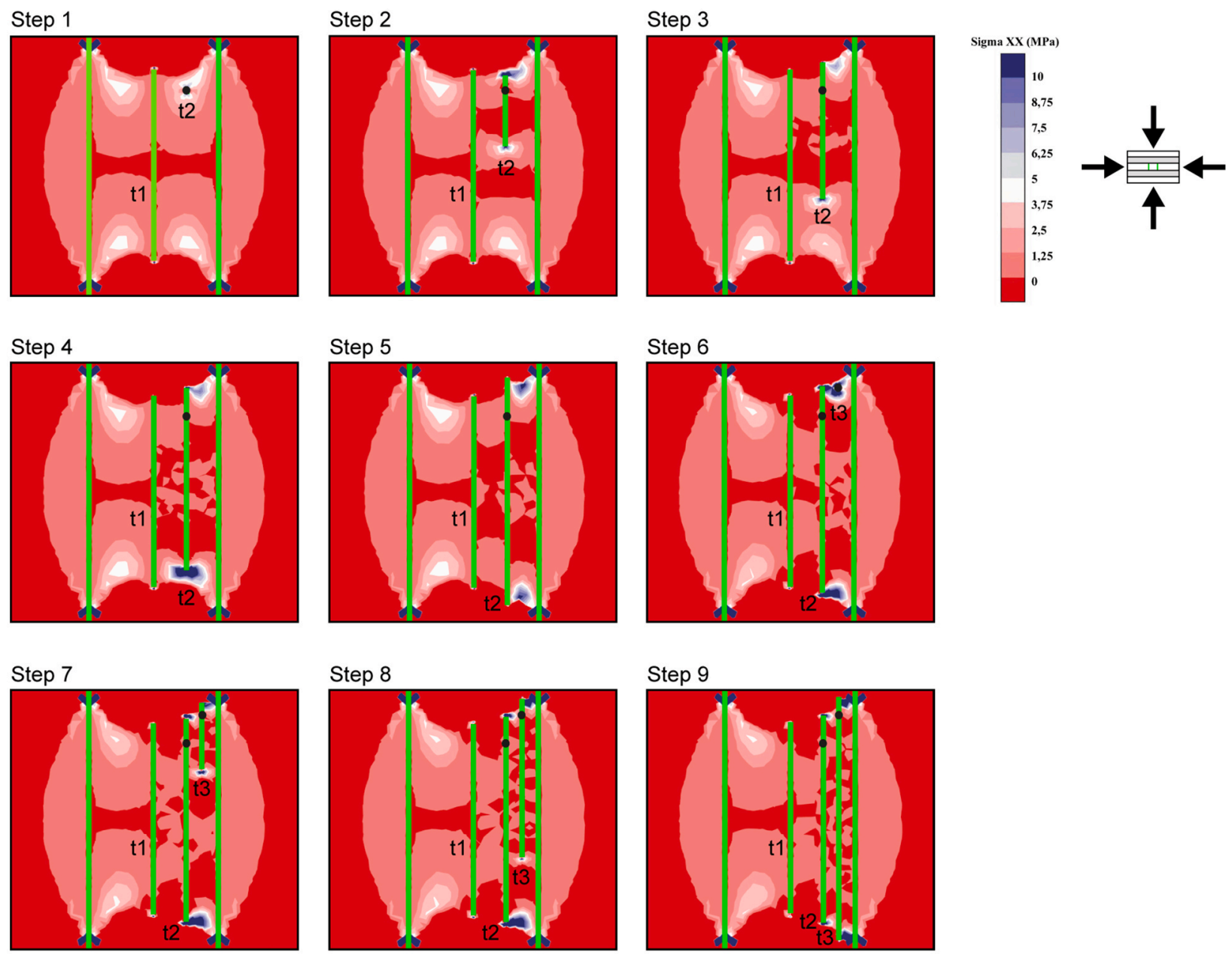

Fig. 13. Propagation of a series of fracture seeds at successive times from newly-developed favorable tensile stress areas appearing near the tips of pre-existing fractures (time $t_{1}$ corresponds to propagation steps a to d of Fig. $5 \mathrm{~b}$, time $t_{2}$ to steps 1 to 5 of the current figure and time $t_{3}$ to steps 6 to 9 ). The black dots indicate the initial location of the propagating fracture seeds. 
incipient fracture corridors to develop by localizing new fractures around the pre-existing ones. We define this mechanism as the tension halo clustering mechanism. It is illustrated for larger initial fracture spacings by Fig. 14c and d Part 1, Fig. 16c Parts 1-2 and Fig. 16d Part 1. In addition, and superimposed onto the previous mechanism, a second possible fracture clustering mechanism, that we define as the sequentially-generated-tension clustering mechanism, is presented in Fig. 11d Part 2 and Fig. 13. This time, the first fracture propagating at $t_{1}$ consumes the energy related to the initial tensile stress existing in the region of interest, apparently impeding further fracture propagations. However, at the end of its propagation, new lobes of tensile stress develop between its tips and the closest pre-existing fracture. A fracture seed located in one of these lobes can then propagate at $t_{2}$, with a final length greater than the earlier fracture. The same process of tensile stress development at fracture tips repeats itself again, supporting further fracture propagation at $t_{3}$. Each new stage of fracture propagation allows reducing the fracture spacing (by two in the cases presented) and a corridor of long, closely-spaced fractures is obtained at the end of the process (Fig. 11d Parts 2-4 and Fig. 13). The minimum fracture spacing obtained in these experiments is equal to $0.0625 \mathrm{~h}$. Additional tests, not presented here, indicate that straight (rectilinear) Mode I fracture propagations could still be obtained for seeds propagating at a distance of $0.05 \mathrm{~h}$ from the pre-existing fractures. Below this threshold value, oblique (curved) propagation is usually promoted because of deviated stress trajectories and the propagating fractures tend to come at the contact with the preexisting ones.

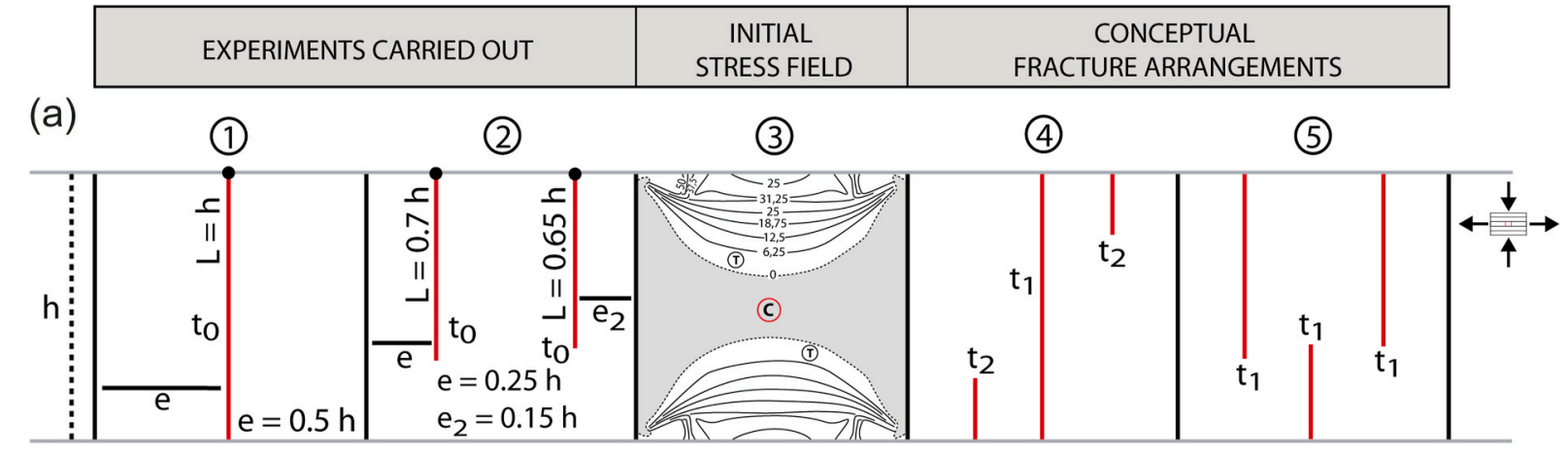

(b)

(2)

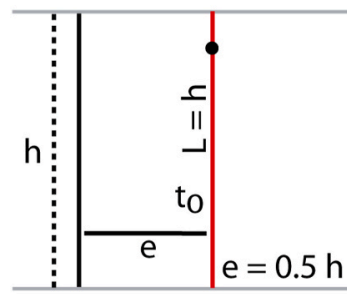

(3)

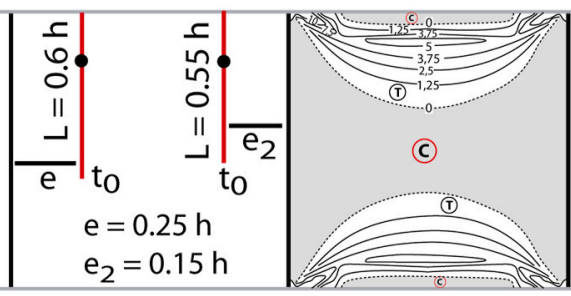

(4)

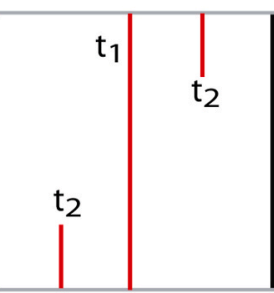

(5)

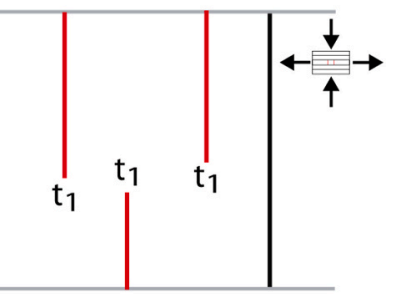

(c)

(2)

(3)

(4)

(5)

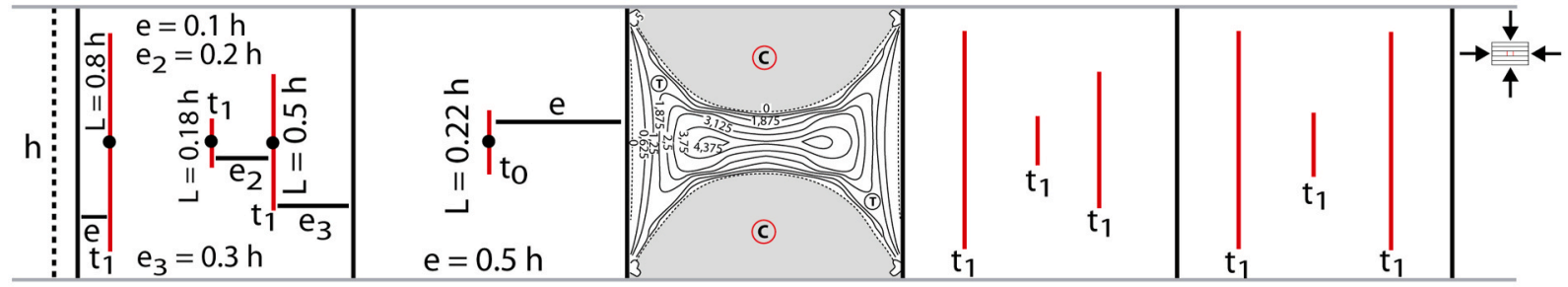

(d)

(1)

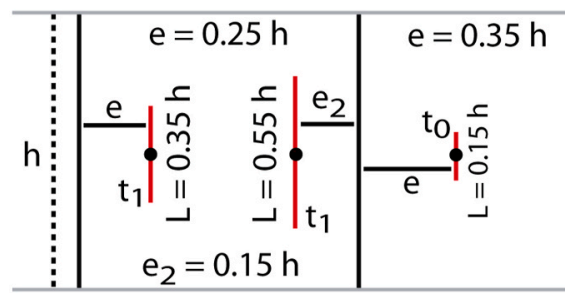

(3)

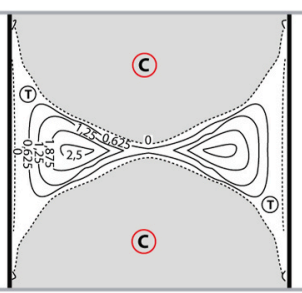

(4)

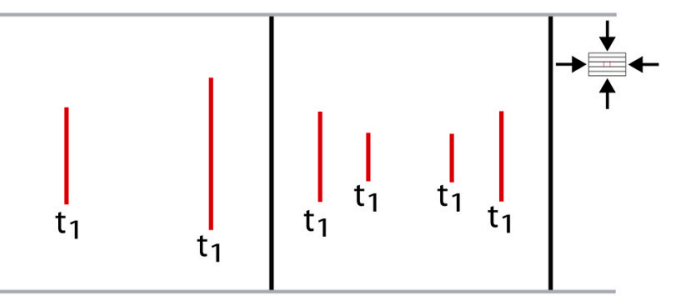

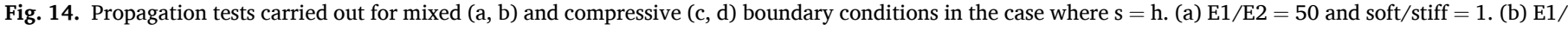
$\mathrm{E} 2=2$ and soft/stiff $=0.025$. (c) $\mathrm{E} 1 / \mathrm{E} 2=10$ and soft/stiff $=0.33$. (d) $\mathrm{E} 1 / \mathrm{E} 2=2$ and soft $/$ stiff $=0.025$. 
In the situation where $\mathrm{s}=\mathrm{h}$ (Fig. $14 \mathrm{c}$ and $\mathrm{d}$ ), fracture propagations are shorter than when $\mathrm{s}=0.5 \mathrm{~h}$ because of more limited tensile stress areas. The fractures reaching the greatest final length are still those located closest to the pre-existing fractures (Fig. 14c and d Part 1), indicating possible fracture clustering associated to the tension halo around the pre-existing fractures, as described earlier. In addition, the same sequentially-generated-tension clustering mechanism illustrated by Figs. $11 \mathrm{~d}$ and 13 still applies. Fig. 15 illustrates the stress distribution in the model of Fig. 14c Part 1. After the propagation of the seeds located close to the pre-existing fractures, new lobes of tensile stress develop in the model, promoting the propagation of a second generation of seeds. The levels of tensile stress in the new lobes are higher in the case where the spacing between the pre-existing fracture and the propagating seed is smaller (left lobes of Fig. 15), indicating that the sequentiallygenerated-tension clustering mechanism is more effective for smaller fracture spacings.

Finally, when $\mathrm{s}=1.5 \mathrm{~h}$, only fracture seeds located close to the preexisting fractures and in the center of the region of interest could propagate, because of very limited tensile stress areas in the region of interest (Fig. 16c and d). As already mentioned, the tension halo clustering mechanism is promoted since tensile stress, hence favorable conditions for fracture propagations, exist only at a close distance from the pre-existing fractures (Fig. 16c and $\mathrm{d}$ Part 3). Finally, the sequentially-generated-tension clustering mechanism is still valid even in this unfavorable model configuration (Fig. 16d Parts 2 and 5).

\subsubsection{Synthesis}

The fracture propagation experiments carried out allowed identifying three fracture clustering mechanisms in the models:

- Under mixed boundary conditions, small fracture corridors formed by a few fractures could develop if seeds located close to a preexisting fracture propagate first in a virgin tensile stress area. This first come first served clustering mechanism is more efficient for larger spacings between the pre-existing fractures;

- Under compressive boundary conditions, fracture corridors could develop:

o By a tension halo clustering mechanism, because fracture seeds propagate better (or only) when located close to the pre-existing fractures. This mechanism is prominent in the case of larger initial fracture spacings;

o By a sequentially-generated-tension clustering mechanism, with new tensile stress appearing in the region between the tips of propagated seeds and the pre-existing fractures, promoting the development of new generations of infill fractures. This mechanism is more efficient for smaller fracture spacings, i.e. higher fracture interactions.

\section{Discussion}

Our study indicates that tensile stress could develop in layered models due to the combined effect of pre-existing open fractures and elastic contrasts between the layers. In particular, the region of interest of the models, bounded and protected by the pre-existing fractures, slightly stretches during the tests even under compressive loading conditions (Fig. 17b,d) while the pre-existing fractures open in one case (mixed boundary conditions, Fig. 17a) and close in the other (compressive boundary conditions, Fig. 17c). The favorable tensile stress conditions identified in the models allow significant openingmode fracturing with clear clustering tendencies to develop. In this section, we discuss the applicability of these results to the development of joints and fracture corridors in natural layered rocks.

First, the effects of temperature and pore and fracture pressure are not modeled in this study. At depth in the subsurface, the temperature is usually high and expected to result in fluid expansion likely to support the opening of fractures and the stress tendencies described in this paper. The same applies to fluid pressure, which helps maintaining the fractures open at depth. The study by Li et al. (2012) describes this positive effect of internal pressure on fracture development in layered models.

Secondly, the layers of our models are bounded, with no interfacial slip. This phenomenon has a significant bearing on the distribution of stress in the models (Ji et al., 1998; Schöpfer et al., 2011). In natural layered rocks, interfacial slip is expected to reduce the levels of tensile stress in the fractured layers compared to the situation of our models, because of reduced mechanical coupling (dissipation processes). Many natural examples of layered rocks with clear evidence of mechanical bounding exist however. For instance, Fig. 18 shows vertically persistent joints within the layered Cretaceous limestones of Djebel Madmar, in Oman. There, despite the repeated succession of beds of limestone and shale (retreating from the cliff front due to easier erosion), fractures managed to propagate across the layer interfaces, indicating that such interfaces were mechanically bounded and could not slip (Helgeson and Aydin, 1991; Cooke and Underwood, 2001). The results obtained in our study apply well to these frequent geological situations.

Thirdly, the stress distributions and fracture clustering mechanisms identified in this study rely on the presence of pre-existing open fractures in brittle layers, including in deep conditions (compressive boundary conditions). We are aware that the presence of open fractures is not obvious at great depth in the subsurface. Natural rocks, however,

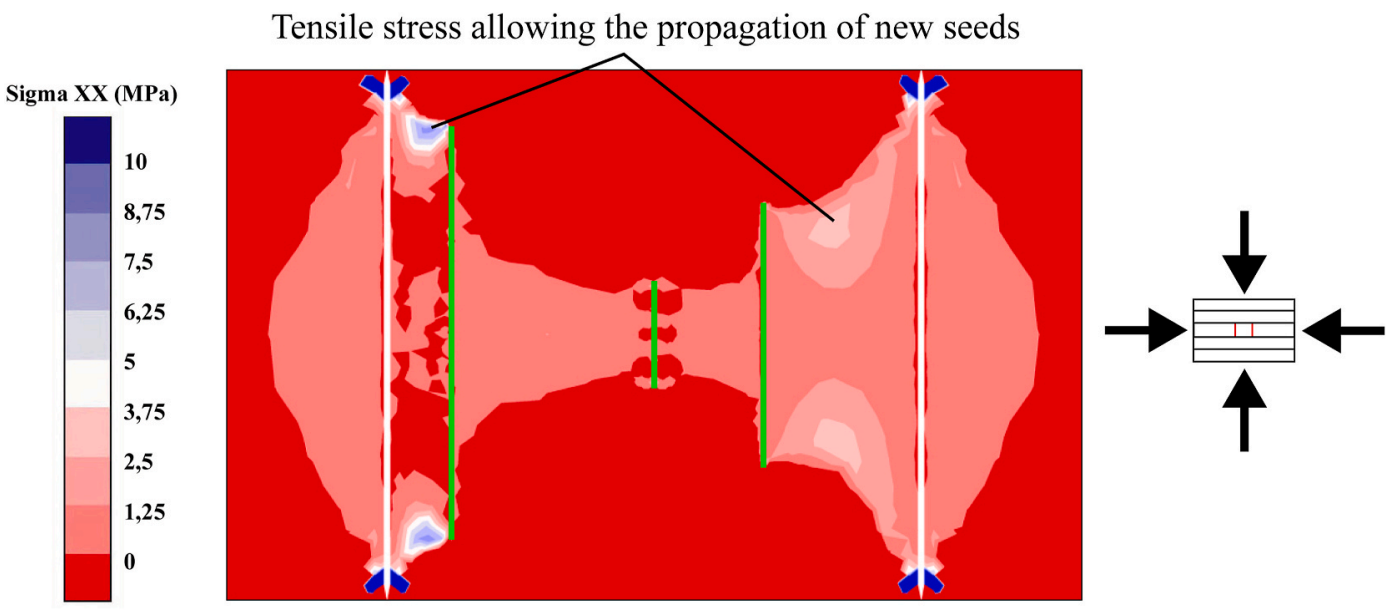

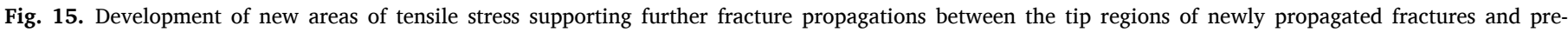
existing fractures. 


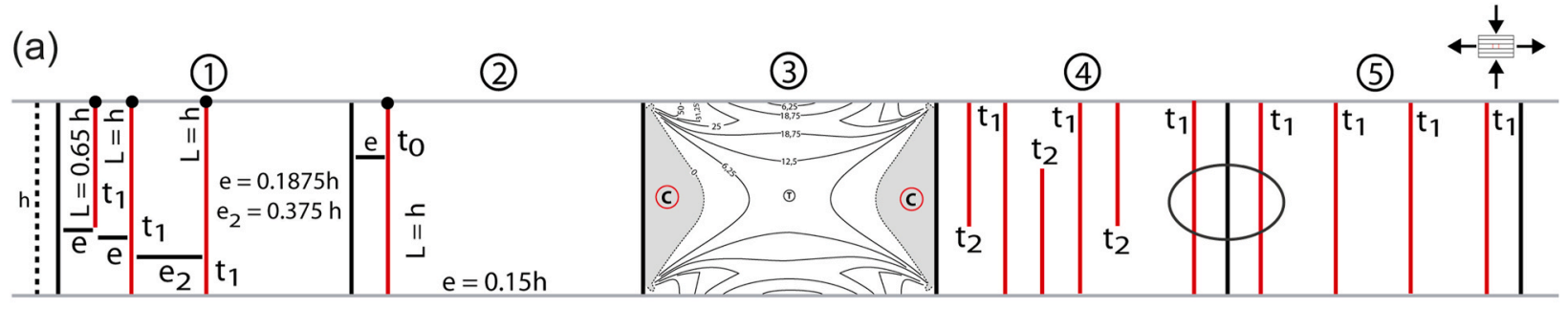

(b) (1) (2) (2) (3) (c)
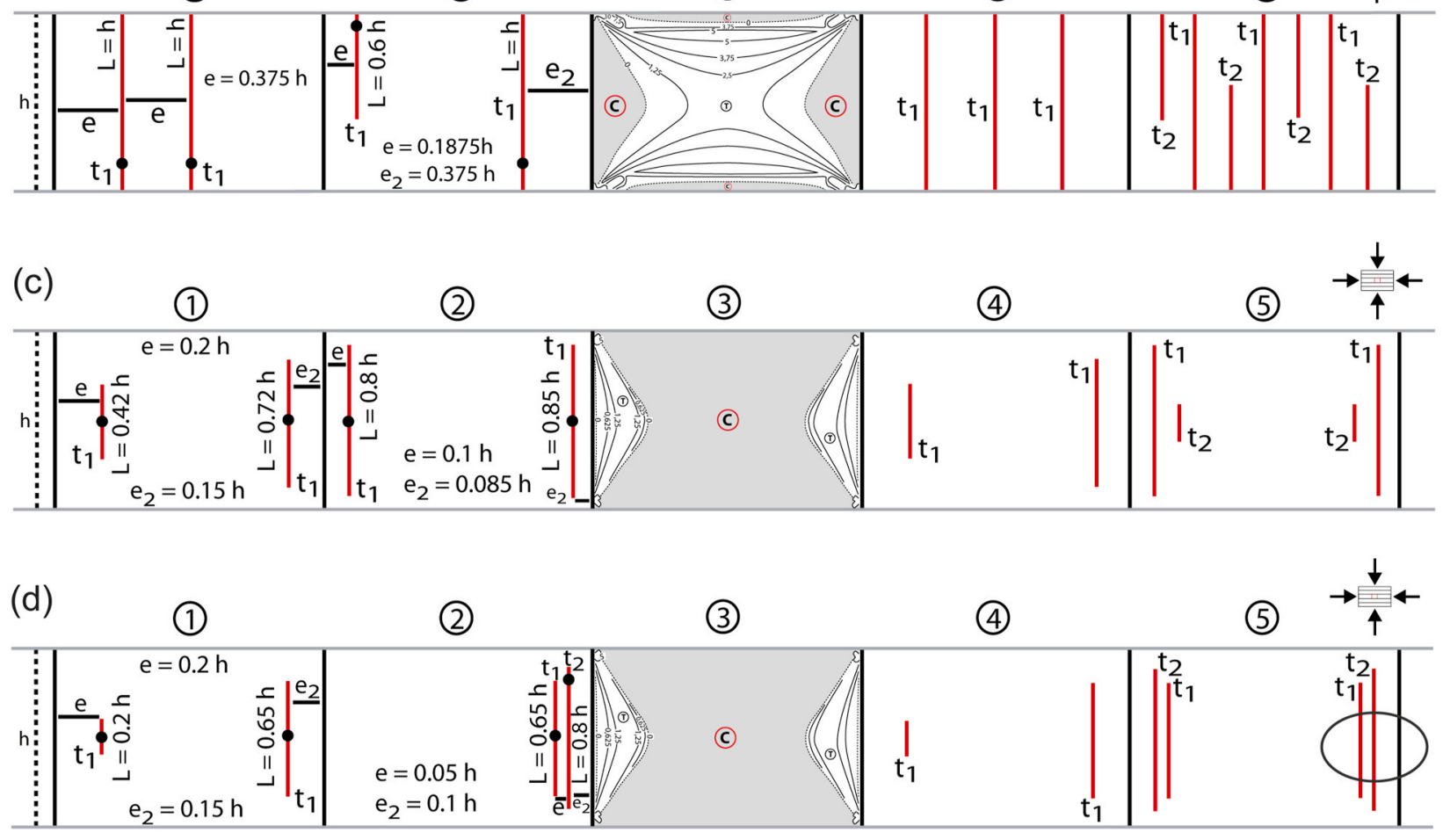

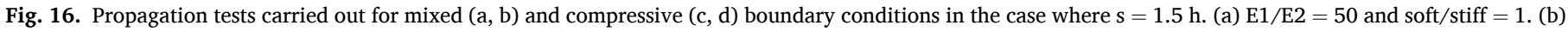
$\mathrm{E} 1 / \mathrm{E} 2=2$ and soft/stiff $=0.025$. (c) $\mathrm{E} 1 / \mathrm{E} 2=50$ and soft/stiff $=0.33$. (d) $\mathrm{E} 1 / \mathrm{E} 2=10$ and soft/stiff $=0.11$.

typically have multiphasic tectonic and burial histories, with the associated thermo-poro-elastic effects, and are frequently fractured at depth (Fig. 2). In particular, examples were documented where layered rocks contain well-developed sets of opening-mode fractures that formed very early and at shallow depth during burial (Bahat, 1989; de Joussineau et al., 2005). In addition, with regard to fracture aperture, clear indications of fracture contribution to flow, hence of conductive open fractures, are found in many hydrocarbon reservoirs in the subsurface (see for example Singha Ray et al., 2012, Fig. 2b).

Fourthly, our models do not consider the lateral propagation of fractures, very important in Nature and investigated by Olson (2004). However, the tensile stress distributions within our models are controlled by the combined effect of fracture spacing, boundary conditions and elastic contrasts between the layers. These parameters are not expected to vary much laterally, over distances of several hundred meters or kilometers. As such, the stress results and fracture clustering mechanisms described in our study are expected to be valid in the along-strike (lateral) direction of the models. Obviously, real 3D fracture propagation involves much more interaction between the propagating fracture seeds than a $2 \mathrm{D}$ situation, but this increased interaction would in turn increase the chance of locally activating the tension halo and sequentially-generated-tension clustering mechanisms that we documented.

Fifthly, our experiments consider the situation of a single stiff fractured layer bounded by soft layers. The fracture clustering mechanisms documented in this paper are of course viable for this simple geological situation, at what can be considered an incipient stage of fracture corridor development. At that stage, the vertical persistency of the corridors is expected to be in the order of a few meters to a few tens of meters, i.e. the maximum thickness of a stiff sedimentary layer. However, our results likely apply also to more mature contexts, when considering this time the situation of a stiff sedimentary pile composed of many layers separated by very thin soft interfaces (bounded layers) and sandwiched between softer sedimentary units. This is typically the case of the $\sim 400$-m-thick pile of sandstones and conglomerates of the Bandagiara plateau shown in Fig. 1e. In this context, the clustering mechanisms described in this paper could apply to the different stages of development of the fracture corridors including the latest, most recent stage where vertically-persistent fracturing affects the entire mechanical unit and stress perturbations occur at the global scale of the unit, which 
(a)

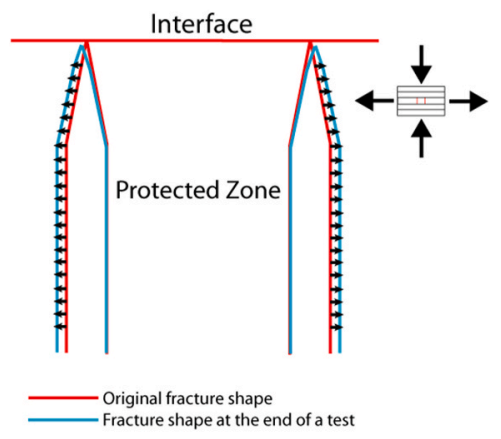

(c)

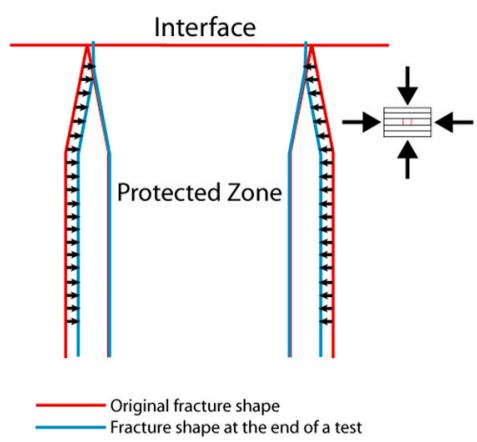

(b)

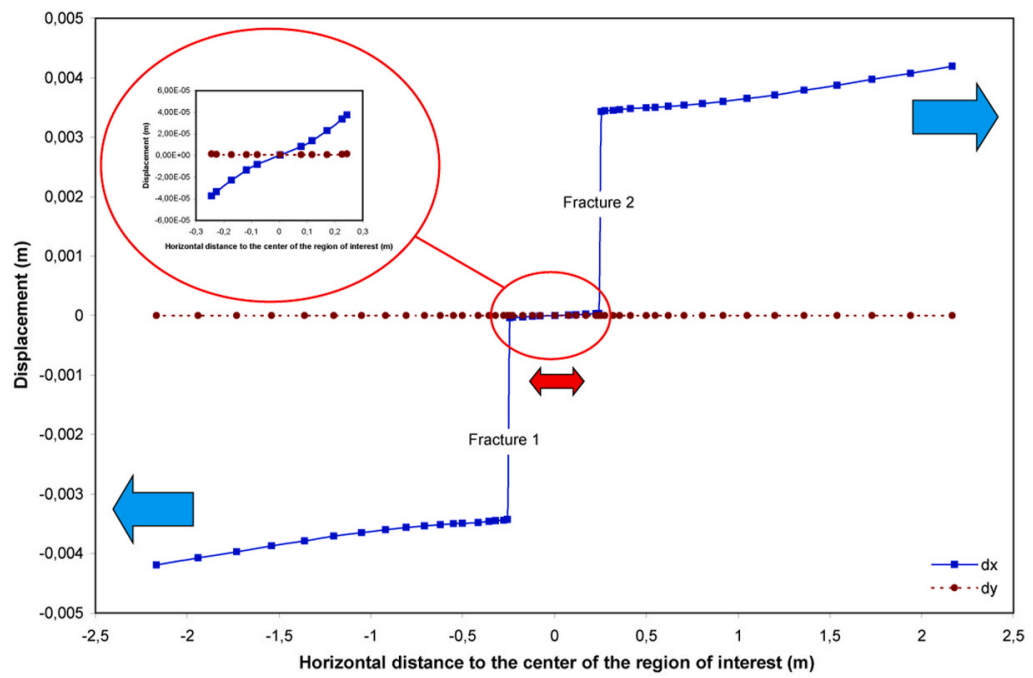

(d)

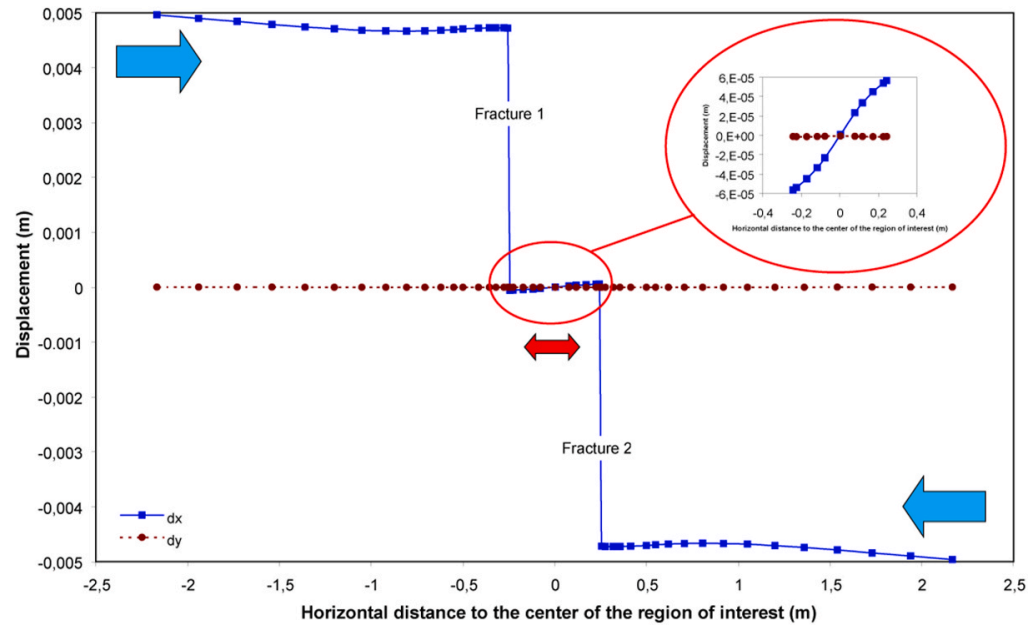

Fig. 17. Deformation of the region of interest of a model under mixed $(a, b)$ and compressive $(c, d)$ boundary conditions. (a) Finite deformation of the pair of fractures at the end of an extension-compression test (magnification factor is 50). The black arrows show the movement of the external wall of the fractures facing the applied displacement. (b) Horizontal (dx) and vertical (dy) finite displacements in the middle of the fractured layer in the same model as in (a). The origin of the $\mathrm{x}$ axis is exactly at mid-distance between the two fractures, and positive displacements in the $\mathrm{x}$-direction correspond to a displacement towards the right of the figure. The whole model, including the region of interest, slightly stretches in the horizontal direction during the test. (c) Finite deformation of the pair of fractures at the end of a biaxial compression test. (d) Horizontal (dx) and vertical (dy) finite displacements in the middle of the fractured layer in the same model as in (c). The region between the two fractures slightly stretches in the horizontal direction while all other regions shorten.

behaves as one large brittle layer. It is highly possible that the largest fracture corridors locate at the position of earlier, smaller-scale corridors controlled by the initial fracture spacing distribution in the unit. The largest fracture corridors can also benefit from the coalescence and merging of several consecutive smaller-scale corridors. This concept of hierarchical development of fracture corridors, which cannot be tested in our experiments, is the likely explanation for wide corridors composed of thousands of fractures as those shown in Fig. 1d and e.

Finally, our experiments indicate that rectilinear fracture propagation can occur at a small distance from a pre-existing fracture. However, below a threshold value, curved propagation is usually promoted because of deviated stress trajectories and the propagating fractures tend to come at the contact with the pre-existing ones. This merging tendency is frequently observed in Nature in the internal architecture of fracture corridors, for very closely spaced fractures. It results in higher fracture connectivity, hence higher global permeability of the fracture corridors.

\section{A new conceptual model for the development of fracture corridors in layered rocks}

In Fig. 19, we present a new conceptual model for the development of fracture corridors in layered rocks, based on the clustering mechanisms identified in this paper and the concepts discussed in the previous Section. 


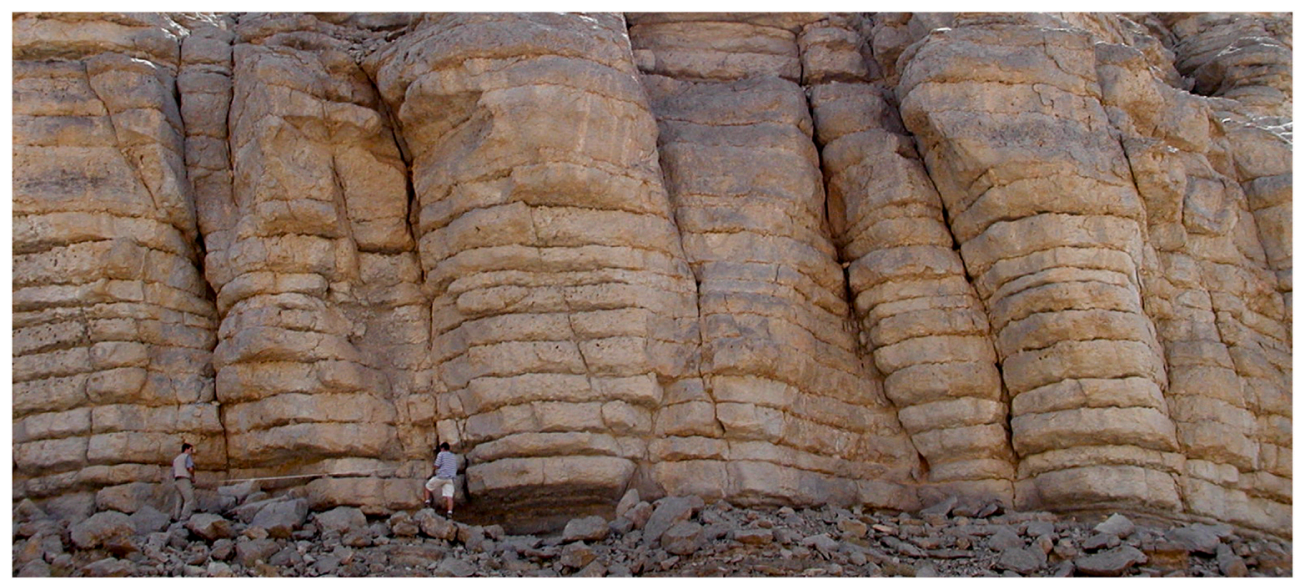

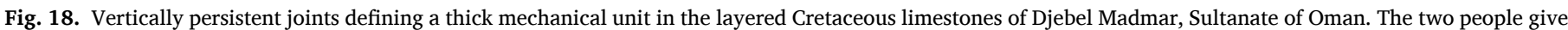
the scale of the photograph.

\subsection{Stage a}

During a first stage of burial, a sedimentary pile composed of a succession of soft (shale, in grey) and stiff (sandstone or limestone, in white) materials fractures in response to a combination of tectonic stresses and compaction/diagenetic mechanisms. The produced fracturing (in blue) is typically poorly developed.

\subsection{Stage $b$}

With increasing depth and horizontal compression, a second generation of fractures (in red) develops in the lobes of tensile stress existing around the pre-existing fractures in areas where the brittle layers are in contact with shale layers or lenses (tension halo clustering mechanism).

Locally, favorable conditions trigger several other stages of fracture propagations, allowing the development of wider and/or denser zones of closely-spaced fractures by the sequentially-generated-tension clustering mechanism.

The tension halo clustering mechanism, associated with scarce open fractures represents an initiation mode for further clustering. The particular distribution of tensile stress centered on the isolated fractures creates the condition for the initiation of new fractures in their immediate vicinity. It is very likely, however, that the sequentially-generatedtension clustering mechanism dominates as soon as the new fractures start to propagate in the layers, because the progressive displacement of their tip regions will create many potential interaction areas, and because new stress concentrations at the tips of propagating fractures are likely to activate seeds (mechanical flaws) situated in their vicinity and formerly inactive.

\subsection{Stage $c$}

In a late stage of burial, new tensile stress areas develop around the fractures due to the increased remote compression. Another generation of fractures (in green) develops in the vicinity of the pre-existing fractures, either by the tension halo and/or sequentially-generated-tension clustering mechanisms, widening the fracture corridors developed in Stage b.

\subsection{Stage $d$}

Finally, when the exhumation and associated stress relaxation occur, tensile stress areas could develop all across the fractured layers, promoting new fracturing (in orange). Under these very favorable conditions, the fracture corridors inherited from the former stages continue their development. Some of them coalesce to form larger-scale features, sometimes vertically cross-cutting the shale layers.

Locally, the first come first served mechanism allows producing narrow corridors formed by a few fractures (areas marked by red stars in Fig. 19). In addition, individual fractures develop in all the brittle layers to consume the existing tensile stress.

The first come first served mechanism, based on the consumption of tensile stress by the first propagating seeds, is in essence a mechanism that results in more or less regular fracture spacings in the fractured layers, since the most favorable stress conditions occur at mid distance between the pre-existing fractures under crack-normal extension. Consequently, the seeds located at mid distance between the pre-exiting fractures have a much higher chance of developing compared with those located at proximity with the pre-existing fractures. The occasional, chance activation of the latter could create limited clustering, in a trend of globally equally spaced fractures.

\section{Conclusions}

This paper investigates how fracture corridors could develop in layered rocks due to the combined effect of pre-existing fractures and elastic contrasts between layers.

The analyses carried out allow identifying situations where horizontal tensile stress promoting further opening-mode fracture propagations develops in the fractured layers under both remote horizontal extension and shortening conditions. The results obtained indicate that boundary conditions play an important role on the stress distribution in the fractured layers. Tensile stress develops at the layer interfaces in the case of horizontal extension, and towards the center of the fractured layers in the case of horizontal compression. These tendencies may explain why some natural fractures initiate at bed interfaces while others initiate in the center of the beds. In addition, the spacing between pre-existing fractures is a crucial parameter controlling the stress distribution (areas of tensile and compressive stress) in the fractured layers. Finally, the elastic contrast between the layers and the soft/stiff ratio both have a limited influence on the tensile stress distribution and values within the fractured layers.

Based on the stress results obtained, quasi-static fracture propagation experiments were carried out in areas of tensile stress using the Griffith theory. Three mechanisms leading to the formation of fracture corridors in natural layered rocks are identified, which do not depend on the elastic parameters of the multilayers. Under compressive boundary conditions, fracture corridors may form due to the particular distribution of tensile stress in lobes centered on the pre-existing fractures when those are highly spaced (tension halo clustering mechanism). In addition, whatever the pre-existing fracture spacing, fracture corridors may develop sequentially due to interactions between earlier fractures 
(a)
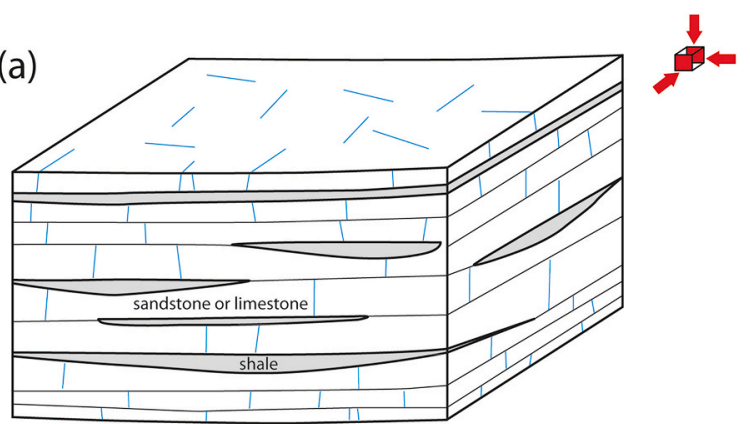

(b)
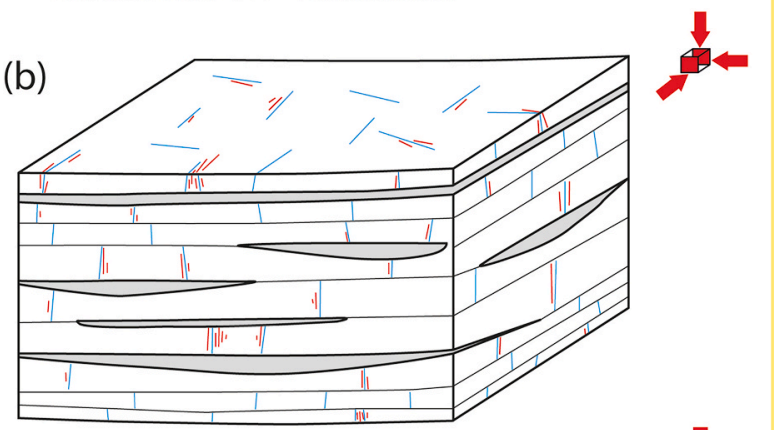

(c)
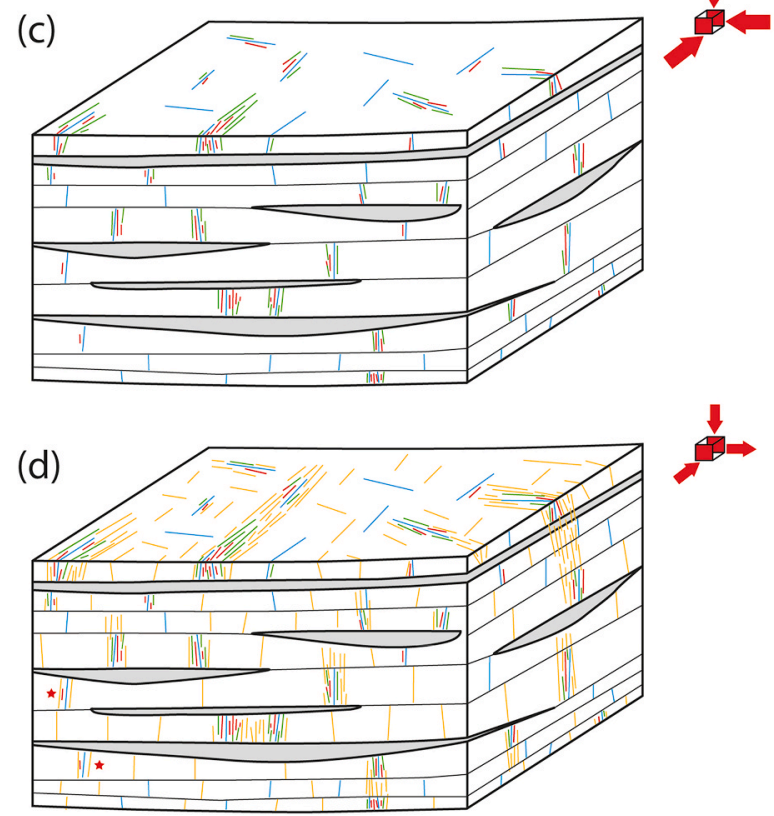

Fig. 19. Conceptual model of fracture corridor development in layered rocks (see text for explanations).

(sequentially-generated-tension clustering mechanism). Finally, in the case of horizontal extension, the formation of small fracture corridors containing a few fractures is possible if fracture seeds located close to a pre-existing fracture propagate first in a virgin tensile stress area (first come first served clustering mechanism).

Based on these results, we propose a new conceptual model for the formation of fracture corridors in the subsurface, with important consequences for the characterization and modeling of fractured reservoirs.

\section{Author statement}

Conceptualization: Ghislain de Joussineau, Jean-Pierre Petit. Methodology: Ghislain de Joussineau, Jean-Pierre Petit. Software: Ghislain de Joussineau. Validation: Ghislain de Joussineau. Formal analysis: Ghislain de Joussineau, Jean-Pierre Petit. Investigation: Ghislain de
Joussineau, Jean-Pierre Petit. Resources: Ghislain de Joussineau, JeanPierre Petit. Data Curation: Ghislain de Joussineau, Jean-Pierre Petit. Methodology: Ghislain de Joussineau, Jean-Pierre Petit. Writing (draft and review): Ghislain de Joussineau. Visualization: Ghislain de Joussineau. Supervision: Ghislain de Joussineau, Jean-Pierre Petit. Project Administration: Jean-Pierre Petit. Funding Acquisition: Ghislain de Joussineau, Jean-Pierre Petit.

\section{Declaration of competing interest}

The authors declare that they have no known competing financial interests or personal relationships that could have appeared to influence the work reported in this paper

\section{Acknowledgements}

This work is dedicated to Ann-Laure and Jean-Claude Moreau, Héloïse and Gérald de Joussineau and all the Covid-19 victims. It was supported by the French Research Ministry (PhD grant to GJ) and Shell International Exploration and Production B.V. We are grateful to the Cornell Fracture Group for access to Franc 2D and technical support. We thank David Peacock and Martin Schöpfer for their reviews that improved the paper, and JSG's Editor Ian Alsop for his handling of the manuscript and support during the publication process. Finally, this study benefited from advice by Stephen Bourne and Joel Ita and discussions with Michel Barquins, Loic Bazalgette, Stéphane Bouissou and Pascal Cortes within the Geo-FracNet research consortium.

\section{References}

Angelier, J., Bergerat, F., Dauteil, O., Villement, T., 1997. Effective tension-shear relationships in extensional fissure swarms, axial rift zone of northeastern Iceland. J. Struct. Geol. 19, 673-685.

Angelier, J., Souffache, B., Barrier, E., Bergerat, F., Bouaziz, S., Bouroz, C., Creuzot, G., Ouali, J., Tricart, P., 1989. Distribution de joints de tension dans un banc rocheux: loi théorique et espacements. Comptes Rendus de l'Académie des Sciences de Paris, Série II 309, 2119-2125.

Atkinson, B.K., 1987. Fracture Mechanics of Rocks. Academic Press, London.

Bahat, D., 1989. Fracture stresses at shallow depths during burial. Tectonophysics 169, 59-65.

Bai, T., Pollard, D.D., 2000a. Fracture spacing in layered rocks: a new explanation based on the stress transition. J. Struct. Geol. 22, 43-57.

Bai, T., Pollard, D.D., 2000b. Closely spaced fractures in layered rocks: initiation mechanism and propagation kinematics. J. Struct. Geol. 22, 1409-1425.

Bai, T., Pollard, D.D., 2001. Getting more for less: the unusual efficiency of fluid flow in fractures. Geophys. Res. Lett. 28, 65-68.

Bai, T., Pollard, D.D., Gao, H., 2000a. Explanation for fracture spacing in layered materials. Nature 403, 753-756.

Bai, T., Pollard, D.D., Gross, M., 2000b. Mechanical prediction of fracture aperture in layered rocks. J. Geophys. Res. 105, 707-721.

Barquins, M., 1985. Les instabilités mécaniques: modèle de représentation des propagations subcritiques et catastrophiques. In: Gratier, J.P. (Ed.), Actes du Colloque CNRS 'les instabilités mécaniques: développement et périodicité', pp. 93-103. Grenoble, 10-11 October 1985.

Bazalgette, L., Petit, J.P., 2007. Fold amplification and style transition involving fractured dip-domain boundaries: buckling experiments in brittle paraffin wax multilayers and comparison with natural examples. In: Lonergan, L., Jolly, R.J.H., Rawnsley, K., Sanderson, D.J. (Eds.), Fractured Reservoirs, vol. 270. Geological Society of London, Special Publications, pp. 157-169.

Bazalgette, L., Petit, J.P., Amrhar, M., Ouanaïmi, H., 2010. Aspects and origins of fractured dip-domain boundaries in folded carbonate rocks. J. Struct. Geol. 32, 523-536.

Becker, A., Gross, M.R., 1996. Mechanism for joint saturation in mechanically layered rocks: an example from southern Israel. Tectonophysics 257, 223-237.

Belayneh, M., Matthäi, S.K., Cosgrove, J.W., 2007. The Implications of Fracture Swarms in the Chalk of SE England on the Tectonic History of the Basin and Their Impact on Fluid Flow in High-Porosity, Low-Permeability Rocks, vol. 272. Geological Society of London, Special Publications, pp. 499-517.

Bevan, T.G., Hancock, P.L., 1986. A late cenozoic regional mesofracture system in southern England and northern France. J. Geol. Soc. 143, 355-362.

Bisdom, K., Gauthier, B.D.M., Bertotti, G., Hardebol, N.J., 2014. Calibrating discrete fracture network models with a carbonate three dimensional outcrop fracture network: implications for naturally fractured reservoir modeling. AAPG (Am. Assoc. Pet. Geol.) Bull. 98, 1351-1376.

Bockel-Rebelle, M.O., Hassall, J.K., Silva, F.P., Lozano, J.A., Al Deeb, M., El Abd Salem, S., Vesseron, M., Al Mehsin, K., 2004. Faults, Fracture Corridors and Diffuse 
Fracturing: Ranking the Main Structural Heterogeneities within Onshore Abu Dhabi Fields. Society of Petroleum Engineers. Paper \# 88676.

Bockel-Rebelle, M.O., Dabbour, Y., El Abd Salem, S., Vesseron, M., Silva, F.P., 2005. Faults and Fracture Corridors - How to Reduce the Structural Uncertainty for Reservoir Management Optimization. Society of Petroleum Engineers. Paper \# 93752.

Bourne, S.J., 2003. Contrast of elastic properties between rock layers as a mechanism fo the initiation and orientation of tensile failure under uniform remote compression. J. Geophys. Res. 108 https://doi.org/10.1029/2001JB001725.

Caetano, H., Niculescu, E., Hozayen, M., El Sayed, R., de Joussineau, G., Games, F., de Haeck, T., Ibert, S., 2014. Fracture Characterization of Carbonate Reservoir with Integration of Dynamic Data. Society of Petroleum Engineers. Paper \# 171973.

Cooke, M.L., Underwood, C.A., 2001. Fracture termination and step-over at bedding interfaces due to frictional slip and interface opening. J. Struct. Geol. 23, 223-238.

Cosentino, L., Coury, Y., Daniel, J.M., Manceau, E., Ravenne, C., Van Lingen, P., Cole, J. Sengul, M., 2001. Integrated Study of a Fractured Middle East Reservoir with Stratiform Super-K Intervals - Part 2: Upscaling and Dual Media Simulation. Society of Petroleum Engineers. Paper \# 68184.

de Joussineau, G., 2003a. Contribution à l'étude du comportement sous contrainte des failles et des fractures de mode I: terrain, et modélisations analogiques et numériques. $\mathrm{PhD}$ Thesis. Université Montpellier II.

de Joussineau, G., 2003b. 2D Numerical Investigation of the Mechanics of Jointing within Layered Rocks: towards the Origin of Fracture Corridors. Technical Report. Shell International Exploration and Production B.V.

de Joussineau, G., Petit, J.P., 2004. 2D Numerical Investigation of Fracture Corridor Development within Layered Rocks. Fractured Reservoirs Conference. The Geological Society of London, Burlington House, London, 16-17 November (London, UK).

de Joussineau, G., Petit, J.P., 2006. Variations in fracture aperture above normal faults: a numerical investigation in 2-D elastic multilayers. J. Struct. Geol. 28, 669-681.

de Joussineau, G., Petit, J.P., 2007. Can tensile stress develop in fractured multilayers under compressive strain conditions? Tectonophysics 432 1-4, 51-62.

de Joussineau, G., Bazalgette, L., Petit, J.P., Lopez, M., 2005. Morphology, intersections, and syn/late-diagenetic origin of vein networks in pelites of the Lodève Permian Basin, Southern France. J. Struct. Geol. 27, 67-87.

de Joussineau, G., Barrett, K., Alessandroni, M., Le Maux, T., 2016. Organization, flow impact and modeling of natural fracture networks in a karstified carbonate bitumen reservoir: an example in the Grosmont formation of the Athabasca Saleski leases, Alberta, Canada. Bull. Can. Petrol. Geol. 64, 291-308.

Elrafie, E., Al-Qahtani, G.D., Agil, M., Rincon, A., Colomar, F.M., 2008. Field Development Plans Optimization by Modeling Fluids Flow Impact and Assessing Intelligent Wells on Reservoir Performance. Society of Petroleum Engineers. Paper \# 117630.

Engelder, T., 1993. Stress Regimes in the Lithosphere. Princeton University Press, New Jersey, USA.

Engelder, T., Peacock, D.C.P., 2001. Joint development normal to regional compression during flexural-flow folding: the Lilstock buttress anticline, Somerset, England: J. Struct. Geol. 23, 259-277.

Fisher, M.P., Gross, M.R., Engelder, T., Greenfield, R.J., 1995. Finite element analysis of the stress distribution around a pressurized crack in a layered elastic medium: implications for the spacing of fluid-driven joints in bedded sedimentary rocks. Tectonophysics 247, 49-64.

Gillespie, P.A., Walsh, J.J., Watterson, J., Bonson, C.G., Manzocchi, T., 2001. Scaling relationships of joint and vein arrays from the Burren, Co. Clare, Ireland. J. Struct. Geol. 23, 183-201.

Griffith, A.A., 1920. The phenomena of rupture and flow in solids. Phil. Trans. Roy. Soc. Lond. A221, 163-197.

Gross, M.R., 1993. The origin and spacing of cross joints: examples from the Monterey Formation, Santa Barbara Coastline, California. J. Struct. Geol. 15, 737-751.

Gross, M.R., Fisher, M.P., Engelder, T., Greenfield, R.J., 1995. Factors controlling joint spacing in interbedded sedimentary rocks: integrating numerical models with field observations from the Monterey Formation, USA. In: Ameen, M.S. (Ed.), Fractography: Fracture Topography as a Tool in Fracture Mechanics and Stress Analysis, vol. 92. Geological Society Special Publications, pp. 215-233.

Gross, M.R., Eyal, Y., 2007. Throughgoing fractures in layered carbonate rocks. Geol. Soc. Am. Bull. 119, 1387-1404.

Hart, B.S., Pearson, R.A., Rawling, G.C., 2002. 3-D seismic horizon-based approaches to fracture-swarm sweet spot definition in tight-gas reservoirs. Lead. Edge 21, 28-35.
Helgeson, D.E., Aydin, A., 1991. Characteristics of joint propagation across layer interfaces in sedimentary rocks. J. Struct. Geol. 13, 897-911.

Ji, S., Zhu, Z., Wang, Z., 1998. Relationship between joint spacing and bed thickness in sedimentary rocks: effects of interbed slip. Geol. Mag. 135, 637-655.

Ladeira, F.L., Price, N.J., 1981. Relationship between fracture spacing and bed thickness. J. Struct. Geol. 3, 179-183.

Laubach, S.E., 1991. Fracture Patterns in Low-Permeability-Sandstone Gas Reservoir Rocks in the Rocky Mountain Region. Society of Petroleum Engineers. Paper \# 21853.

Laubach, S.E., Mace, R.E., Nance, H.S., 1995. Fault and joint swarms in a normal fault zone. In: Rossmanith, H.P. (Ed.), Mechanics of Jointed and Faulted Rocks. Balkema, Rotterdam, The Netherlands, pp. 305-309.

Laubach, S.E., Lamarche, J., Gauthier, B.D.M., Dunne, W.M., Sanderson, D.J., 2018. Spatial arrangement of faults and opening-mode fractures. J. Struct. Geol. 108, 2-15.

Li, L.C., Tang, C.A., Wang, S.Y., 2012. A numerical investigation of fracture infilling and spacing in layered rocks subjected to hydro-mechanical loading. Rock Mech. Rock Eng. 45, 753-765.

Mandl, G., 1988. Mechanics of Tectonic Faulting Part 1: Models and Basic Concepts. Elsevier, Amsterdam - Oxford - New York - Tokyo.

Marrett, R., Wells Gale, J.F., Gomez, L.A., Laubach, S.E., 2017. Correlation analysis of fracture arrangement in space. J. Struct. Geol. 108, 16-33.

Martel, S.J., 1994. Effects of cohesive zones on small faults and implications for secondary fracturing and fault trace geometry. J. Struct. Geol. 19, 835-847.

McConaughy, D.T., Engelder, T., 2001. Joint initiation in bedded clastic rocks. J. Struct. Geol. 23, 203-221.

Narr, W., Suppe, J., 1991. Joint spacing in sedimentary rocks. J. Struct. Geol. 13, 1037-1048.

Ogata, K., Senger, K., Braathen, A., Tveranger, J., 2014. Fracture corridors as seal-bypass systems in siliciclastic reservoir-caprock successions: field-based insights from the Jurassic Entrada Formation (SE Utah, USA). J. Struct. Geol. 66, 162-187.

Olson, J.E., 2004. Predicting fracture swarms - the influence of the subcritical crack growth and the crack-tip process zone on joint spacing in rock. In: Cosgrove, J.W., Engelder, T. (Eds.), The Initiation, Propagation and Arrest of Joints and Other Fractures, vol. 231. Geological Society of London, Special Publications, pp. 73-88.

Peacock, D.C.P., Nixon, C.W., Rotevatn, A., Sanderson, D.J., Zuluaga, L.F., 2016. Glossary of fault and other fracture networks. J. Struct. Geol. 92, 12-19.

Petit, J.P., Mattauer, M., 1995. Paleostress superimposition deduced from mesoscale structures in limestone: the Matelles exposure, Languedoc, France. J. Struct. Geol. 17, 245-256.

Pollard, D.D., Segall, P., 1987. Theoretical displacements and stresses near fractures in rock: with applications to faults, joints, veins, dikes, and solution surfaces. In: Atkinson, B.K. (Ed.), Fracture Mechanics of Rocks. Academic Press, London, pp. 277-349.

Pollard, D.D., Aydin, A., 1988. Progress in understanding jointing over the past century. Geol. Soc. Am. Bull. 100, 1181-1204.

Price, N.J., 1966. Fault and Joint Development in Brittle and Semi-brittle Rocks. Pergamon Press, New York.

Price, N.J., Cosgrove, J.W., 1990. Analysis of Geological Structures. Cambridge University Press, England.

Rabinovitch, A., Bahat, D., 1999. Model of joint spacing distribution based on shadow compliance. J. Geophys. Res. 104, 4877-4886.

Raju, I.S., 1987. Calculation of strain-energy release rates with higher order and singular finite elements. Eng. Fract. Mech. 28, 251-274.

Rybicki, E.F., Kanninen, M.F., 1977. A finite element calculation of stress intensity factors by a modified fracture closure integral. Eng. Fract. Mech. 9, 931-938.

Schöpfer, M.P.J., Arslan, A., Walsh, J.J., Childs, C., 2011. Reconciliation of contrasting theories for fracture spacing in layered rocks. J. Struct. Geol. 33, 551-565.

Singha Ray, D., Al-Shamali, A., Verma, N., Matar, S., de Groen, V., de Joussineau, G., Ghilardini, L., Le Maux, T., Al-Khamees, W., 2012. Characterizing and modeling natural fracture networks in a tight carbonate reservoir in the Middle East- a methodology. Bull. Geol. Soc. Malays. 58, 29-35.

Schultz, R.A., Fossen, H., 2008. Terminology for structural discontinuities. AAPG (Am. Assoc. Pet. Geol.) Bull. 92, 853-867.

Souque, C., Knipe, R.J., Davies, R.K., Jones, P., Welch, M.J., Lorenz, J., 2019. Fracture corridors and fault reactivation: example from the Chalk, Isle of Thanet, kent, England. J. Struct. Geol. 122, 11-26.

Wawrzynek, P.A., Ingraffea, A.R., 1987. Interactive finite element analysis of fracture processes: an integrated approach. Theor. Appl. Fract. Mech. 8, 137-150. 